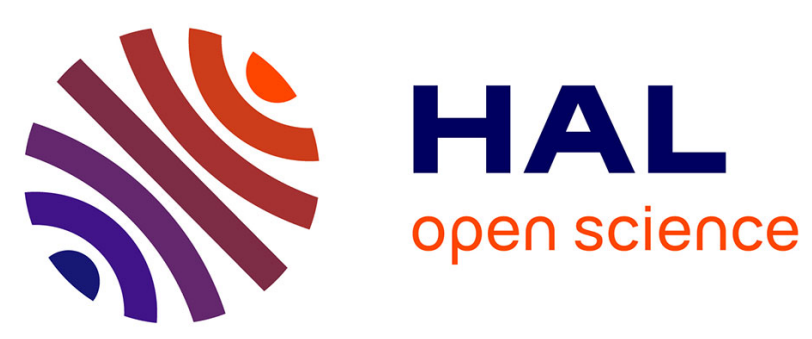

\title{
Population, land, and growth
}

Claire Loupias, Bertrand Wigniolle

\section{To cite this version:}

Claire Loupias, Bertrand Wigniolle. Population, land, and growth. Economic Modelling, 2013, 31, pp.223-237. 10.1016/j.econmod.2012.11.006 . halshs-00823255

\section{HAL Id: halshs-00823255 \\ https://shs.hal.science/halshs-00823255}

Submitted on 16 May 2013

HAL is a multi-disciplinary open access archive for the deposit and dissemination of scientific research documents, whether they are published or not. The documents may come from teaching and research institutions in France or abroad, or from public or private research centers.
L'archive ouverte pluridisciplinaire HAL, est destinée au dépôt et à la diffusion de documents scientifiques de niveau recherche, publiés ou non, émanant des établissements d'enseignement et de recherche français ou étrangers, des laboratoires publics ou privés. 


\title{
Population, land, and growth ${ }^{1}$
}

\author{
Claire Loupias $^{a}$ and Bertrand Wigniolle ${ }^{b}$ \\ ${ }^{a}$ Université d'Evry-Val-d'Essonne, EPEE, TEPP (FRCNRS 3126) \\ Phone : 33 (0) 169477131 \\ Fax : 33 (0) 169477050 \\ claire.loupias@univ-evry.fr \\ ${ }^{b}$ Paris School of Economics, Université Paris 1 Panthéon-Sorbonne \\ CES, 106-112 bd. de l'Hôpital \\ 75647, Paris cedex 13 \\ France
}

Phone : 33 (0) 144078198

Fax : 33 (0) 144078231

wignioll@univ-paris1.fr

25 october 2012

\begin{abstract}
${ }^{1}$ We are grateful to an anonymous referee for very constructive comments. We thank the dynare team and in particular, Stéphane Adjemian, Michel Juillard, and Ferhat Mihoubi for their help with the simulations. We also thank participants to Public Economic Theory conference in Galway (2009), specially Raouf Boucekkine and David de la Croix. We are grateful to participants at the Society for the Advancement of Economic Theory conference in Ischia (2009), and participants to the Journée Dynamique in Lille (2009) and specially to Thomas Seegmuller. We have also benefited from helpful comments at the EPEE seminar at Evry University. The usual disclaimers apply.
\end{abstract}




\begin{abstract}
This paper suggests a new explanation for changes in economic and population growth with a long run perspective, emphasizing the role of land in the development process. Starting from a pre-industrialization state called the "Malthusian regime", land and labor are the main production factors. The size of population is limited by the quantity of land available for households and by incomes. Technical progress driven by a "Boserupian effect" may push the economy towards a take-off regime. In this regime, capital accumulation begins and a "learning-by-doing" effect in production takes over from the "Boserupian effect". If this effect is strong enough, the economy can reach an "ultimate growth regime". In the different phases, land plays a crucial role.
\end{abstract}

Keywords: endogenous fertility, land, endogenous growth.

JEL Classification: D9, J13, O11, R21. 


\section{Introduction}

This paper is a contribution to the unified growth theory emphasizing the role of land and technological progress in economic and population growth. In a long run perspective, land seems a very important variable in the growth process, that deserves a particular study. Our approach is particularly related to two recent articles that have made a breakthrough on the theory of population evolution and growth: Galor and Weil (2000) and Hansen and Prescott (2002).

Galor and Weil (2000) develop a growth model that may explain the joint historical dynamics of education, population, and technology. They are able to reproduce changes in economic growth and population through three regimes: Malthusian, Post-Malthusian, and Modern Growth. Our approach differs from theirs in two key ways. First, land plays a limited role in their model: they assume that the return on land is zero and that the ownership of land is public. Secondly, their model allows population to increase with no bound and population density is not a brake on population growth. We depart from Galor and Weil (2000) by including a true land market with endogenous rent and prices. This true market, combined with a congestion effect on the use of land, induces an upper bound on population size. This is consistent with the usual long run scenario on population from the United Nations (2004).

Hansen and Prescott (2002) give an explanation of fertility behaviors during the industrialization process that emphasizes the role of land. This process is due to the substitution of capital to land in production, driven by biased technical progress in favor of the less land-intensive technology. In their story, population growth is based on an inverse U-shaped functional form of consumption inspired by Malthus (1798). Their model includes a true land market, but both sectors have technologies based on specific exogenous technical progress. Our approach complements Hansen and Prescott (2002) in two ways. First, we introduce endogenous fertility behaviors. The fertility decisions depend on different parameters of cost including a cost in time for parents and a housing cost related to the price of land. Secondly, we also depart from Hansen and Prescott (2002) by incorporating endogenous technical progress. This technical progress results from the increase in population density, that stimulates innovations, and from learning by doing. It induces a substitution of capital to land as in Hansen and Prescott (2002).

Our approach can also be related to Kremer (1993) who developed a model emphasizing interactions between technology and population. This model leads to a testable law of population dynamics that is not rejected by the data on a very long historical period. Our model develops the micro- 
foundations of behaviors that underlie the interactions between technology and population. This allow us to generate a demographic transition without Kremer's assumptions that the population growth rate increases with the level of population at low levels of income and decreases with the level of population at high levels of income.

We develop an overlapping generations model in which fertility is endogenous. The utility of the parents is a function of good consumptions, of the number of their children, and of the consumption of a fixed asset: land. Each child implies a financial cost and induces a congestion effect on the utility of land. In our analysis, land can be used both as a production factor and as housing services for households. As a production factor, land is an income source for households. Under the form of housing services, land gives utility to households. Moreover, as the demand for housing services depends on the number of children, land is also related to fertility behaviors.

To complement our model we introduce two types of survival probabilities: a child survival rate and an adult survival rate. As shown in Aghion et al. (2010), improvement in life expectancy has a significantly positive impact on per capita GDP growth.

The production technology uses three factors: capital, land, and labor. The productivity of capital benefits from technical progress. Technical progress is driven by two effects: a "Boserupian effect" and a "learning-bydoing effect".

The first effect follows Boserup (1965, 1976), for whom the density of population may stimulate the incentives to innovate, in order to increase productivity. Boserup has studied the early stages of development, and was concerned with innovations in agriculture. She claims that "sustained demographic growth among primitive peoples does not always result in deterioration of the environment, because the possibility exists that the population, when it outgrows the carrying capacity of the land with the existing subsistence technology, may change to another subsistence system with a higher carrying capacity. Sometimes this change is even facilitated by the transformation of the environment, for instance, by the replacement of forest by bush or grassland, which forces the population to shift to bush fallow or grass fallow instead of forest fallow and to introduce types of tools that can cope with grassy weeds." This idea of a positive effect of the density of population on innovation has also been emphazised by several authors. Kremer (1993), incorporing ideas of Kuznets (1960), argues that "even if each person's research productivity is independent of population, total research output will increase with population due to the nonrivalry of technology".

The second effect is inspired by the Romer (1986) model: the knowledge 
that was acquired in production in the past increases current productivity. As in Romer (1986), this knowledge can be measured by a proxy variable which is the capital stock.

The economy in our model experiences different stages of development as suggested by Rostow (1959). The analysis firstly focuses on a country starting from a pre-industrialization state. Land and labor are the main production factors. The size of population is limited by the quantity of land available for households and by incomes. This pre-industrialization state is called the "Malthusian regime".

During this phase, some innovations can appear, driven by the "Boserupian effect". If this technical progress is marked enough, the economy can jump out of this Malthusian regime, to undergo a take-off phase. But in the converse case, the economy remains trapped in the stationary "Malthusian regime".

In the take-off regime, the economy begins to accumulate physical capital. The role of land in production becomes less important. A "learning-bydoing" effect in production takes over from the "Boserupian effect". Productivity increases as incomes and population rise. If this "learning-by-doing" effect is strong enough, the economy can reach an "ultimate growth regime".

In the "ultimate growth regime", the economy grows at a constant positive rate. Population converges towards a constant size, as its expansion is limited by land.

In the different phases, land plays a crucial role. ${ }^{1}$ In the "Malthusian regime", a high population density gives incentives to innovate by the "Boserup effect". Therefore, starting with a lower endowment of land or with a higher population size allows a country to reach the take-off phase earlier. In the second phase, when the "learning-by-doing" effect becomes the engine of growth, the size of land has a positive effect on development and thus on the possibility of reaching the third phase. For given technological parameters, a minimum endowment of land is required to reach the ultimate growth regime associated with a positive growth rate. In the third phase, the value of the long run growth increases with the land endowment. The interpretation of this result is that our production technology exhibits the usual property of a scale effect, as in many endogenous growth models. As returns to scale are increasing, the size of population has a positive effect on the long run growth rate. But population size is bounded by land endowment in our model.

\footnotetext{
${ }^{1}$ Allowing for capital accumulation and property rights over land considerably complicates the model, compared to Galor and Weil (2000). The quantity of capital has to be set to equalize its marginal product to the equilibrium interest rate, whereas the price of land has to follow a path such that the total return on land (rent plus net price appreciation) is also equal to the interest rate.
} 
Mortality rates also play a key role in take-off. Mortality is introduced in the model through two survival rates: the survival rate of children and the survival rate of adults. An increase in the survival rate of children reduces the cost of a surviving child. An increase in the survival rate of adults increases their propensity to save, and thus favours capital accumulation. Historically, the Malthusian demographic regime had been characterized by high levels of both fertility and mortality. A decrease in mortality rates can induce both transitions: from the Malthusian to the take-off regime and from the take-off to the ultimate growth regime.

Numerical examples of transition from Malthusian stationary state to the ultimate growth regime are provided at the end of the paper. These examples emphasize the role of the learning by doing effect and of the different mortality parameters in demographic transition and in economic take-off.

Our analysis is related to several strands of literature. First, different authors have stressed the importance of an unbalanced growth process. Galor and Moav (2004) develop a growth theory that describes the replacement of physical capital accumulation by human capital accumulation as a prime engine of growth along the process of development. Kongsamut et al. (2001) propose a model of unbalanced growth, in which the growth process leads to a massive reallocation of labor from agriculture to manufacturing and services.

Secondly, other papers give a crucial role to land in the growth process. Galor et al. (2009) suggest that inequality in the distribution of land ownership may postpone or prevent take-off. Landowners affect the political process and postpone the implementation of education. Brunt and GarciaPenalosa (2010) study the interactions between industrialization and urbanization. They point out a new mechanism that could drive technological change: the population density in cities may trigger the creation and diffusion of knowledge. Their paper provides another interpretation of the "Boserup effect" introduced in our framework: a high density of population leads to more innovation and technological progress.

Section Two presents the model. Section Three analyzes the dynamics of the intertemporal equilibrium. Section Four shows how the dynamics allow us to isolate different phases in the development process. Section Five presents a parametrization of the model that generates "realistic" numerical solutions. Section Six concludes and Section Seven gives references. A last section is devoted to technical appendixes. 


\section{The Model}

We develop a two-period overlapping generations model à la Diamond (1965) where fertility is endogenous. The life of an agent is affected by two exogenous mortality risks. In childhood, he/she has a probability $\eta$ to survive and in adulthood, he/she has a probability $p$ to get old. The number of units of labor is equal to the number of young people and thus determined by households' fertility decisions in the preceding period. In every period the economy produces a single homogenous good, using land, labor, and capital as inputs. Production benefits from a biased technical progress in favor of capital $A_{t}$. The single good is used both for consumption and capital accumulation. Land is a fixed factor, that includes agricultural land, business building, and housing. Services of land may be used both by firms as an input in the production process and by households. For the sake of simplicity, its supply is assumed to be constant and exogenous.

A change in technical progress or in survival probabilities allow us to focus on three different mechanisms to escape from the Malthusian regime.

\subsection{The firm}

Production occurs according to a constant-returns-to-scale technology that is subject to endogenous technological progress. The output produced at time $t, Y_{t}$, is:

$$
Y_{t}=F\left(A_{t} K_{t}, L_{t}, X_{t}\right)
$$

where $K_{t}, L_{t}$, and $X_{t}$ are the quantities of capital, labor, and land employed in production at time $t$. A simple form is assumed for the theoretical model:

$$
F\left(A_{t} K_{t}, L_{t}, X_{t}\right)=\left[\lambda A_{t} K_{t}+(1-\lambda) X_{t}\right]^{\alpha} L_{t}^{1-\alpha}
$$

with $0<\alpha<1,0<\lambda<1$, and $A_{t}>0$. $A_{t}$ represents the endogenously determined technological level at time $t$. Technological progress does not apply to land but to capital. This is a shortcut to point out that technological progress is particularly capital-oriented. This is in line with Hansen and Prescott (2002) who assume that the technology using land as a production factor has a lower growth rate in technical progress. As technical progress increases, capital is substituted to land in the production process. Perfect substitution between capital and land is assumed in order to get some tractability of the model. The aggregate formulation of the production function (2) can be interpreted as a reduced form of a two sector model $\grave{a} l a$ 
Hansen and Prescott. Let us assume a sector one more intensive in land

$$
F^{1}\left(L_{t}^{1}, X_{t}\right)=\left[(1-\lambda) X_{t}\right]^{\alpha}\left(L_{t}^{1}\right)^{1-\alpha}
$$

and a sector two more intensive in capital

$$
F^{2}\left(A_{t} K_{t}, L_{t}^{2}\right)=\left(\lambda A_{t} K_{t}\right)^{\alpha}\left(L_{t}^{2}\right)^{1-\alpha}
$$

where $L_{t}^{1}$ is the quantity of labor in sector one and $L_{t}^{2}$ the quantity of labor in sector two. Along a competitive equilibrium, $L_{t}^{1}$ and $L_{t}^{2}$ are allocated optimally among the two sectors, and aggregate production is given by (2). See Appendix 1 for more details.

This theoretical case can be viewed as a limit case of a more general Constant Elasticity Substitution production function

$$
F\left(A_{t} K_{t}, L_{t}, X_{t}\right)=\left[\lambda\left(A_{t} K_{t}\right)^{1-\frac{1}{\varepsilon}}+(1-\lambda) X_{t}^{1-\frac{1}{\varepsilon}}\right]^{\frac{\varepsilon \alpha}{\varepsilon-1}} L_{t}^{1-\alpha}
$$

that will be examined in the section on simulations.

The capital is fully depreciated in one period. The number of units of labor is determined by households' decisions in the preceding period regarding the number of their children. Households have property rights over land. The land used as an input by the firm is rented to households. The return on land has therefore to be computed and compared to its equilibrium price taken as given by the firm.

With the production technology (2), capital will be used in production, only if the technical progress $A_{t}$ is high enough. As $A_{t}$ increases, the demand for capital becomes positive, and the demand for land $X_{t}$ decreases and may even cancel out. This lower bound on $X_{t}$ could be set to any positive value with a small modification of the production function and has been kept to zero only for tractability. This last point is due to the assumption of perfect substitutability between capital and land which is convenient to allow some tractability of the model. With production (3) the demand for land remains positive, even if it may go to zero.

The firm maximizes its profit, taken the wage rate, the interest rate, the rent rate, and the level of technology as given.

First order conditions for the optimization problem are derived below. All markets are perfectly competitive. On the labor market the quantity of labor used in production $L_{t}$ is equal to $N_{t}$ the number of young households at period $t .^{2}$ Defining, $k_{t} \equiv \frac{K_{t}}{N_{t}}$ and $x_{t} \equiv \frac{X_{t}}{N_{t}}$, the competitive wage is:

\footnotetext{
${ }^{2}$ Each young agent provides one unit of labor. The old are retired.
} 


$$
w_{t}=(1-\alpha)\left[\lambda\left(A_{t} k_{t}\right)+(1-\lambda) x_{t}\right]^{\alpha}
$$

Marginal productivities of capital and land are respectively defined as:

$$
\begin{aligned}
R_{t} & \equiv \alpha \lambda A_{t}\left[\lambda\left(A_{t} k_{t}\right)+(1-\lambda) x_{t}\right]^{\alpha-1} \\
\chi_{t} & \equiv \alpha(1-\lambda)\left[\lambda\left(A_{t} k_{t}\right)+(1-\lambda) x_{t}\right]^{\alpha-1}
\end{aligned}
$$

Define $\pi_{t}$ as the competitive rent rate on land and $\rho_{t}$ as the competitive gross return on savings. The solution of the optimization problem is the following. If for $k_{t}=0, R_{t}=\alpha \lambda A_{t}\left[(1-\lambda) x_{t}\right]^{\alpha-1}<\rho_{t}$, the firm does not use any capital. If $\alpha \lambda A_{t}\left[(1-\lambda) x_{t}\right]^{\alpha-1}>\rho_{t}$, then $k_{t}>0$ at the equilibrium and $R_{t}=\rho_{t}$.

If for $x_{t}=0, \chi_{t}=\alpha(1-\lambda)\left[\lambda\left(A_{t} k_{t}\right)\right]^{\alpha-1}<\pi_{t}$, the firm does not use land. If $\alpha(1-\lambda)\left[\lambda\left(A_{t} k_{t}\right)\right]^{\alpha-1}>\pi_{t}$, then $x_{t}>0$ at the equilibrium and $\chi_{t}=\pi_{t}$.

\subsection{Technology}

We assume the existence of two sources of technical progress. The first one, called the "Boserup effect", assumes that the density of population favors technical progress, as demographic pressure stimulates innovation. The second one, called the "Learning by doing effect", posits that the knowledge acquired in past production increases current productivity. This knowledge, as suggested by Romer (1986), is represented by the aggregate capital stock of the economy (in the spirit of $A K$ models). Thus, technical progress is an increasing function of both population density and $K_{t}$.

$$
A_{t}=g\left(\frac{N_{t}}{\bar{X}}, K_{t}\right)
$$

We use the particular function below:

$$
A_{t}=\left[\mu\left(A_{N}\left(\frac{N_{t}}{\bar{X}}\right)^{\beta}\right)^{1-\frac{1}{\nu}}+(1-\mu)\left(A_{K}^{\frac{1}{\alpha}} K_{t}^{\left(\frac{1}{\alpha}-1\right)}\right)^{1-\frac{1}{\nu}}\right]^{\frac{\nu}{\nu-1}}
$$

with $\nu>1$ and $0<\mu<1 . \bar{X}$ is the total amount of land available in the economy. Land must be viewed as normalized with respect to the quality of soil and the climate.

This paper adopts a broad view of capital, including fencing, irrigation, agricultural machinery, farm equipments etc... This is consistent with our assumption that the Boserupian effect in the technical progress is capital augmenting. 
$A_{N}$ and $A_{K}$ are positive parameters. At the beginning of the growth process, the level of capital is low, and technological progress increases with the size of the population. Then, as the technological progress increases, the level of capital increases itself and magnifies the increase in the level of technology. As the size of the population stabilizes, technological progress is only driven by capital accumulation.

\subsection{Households}

In each period $t$ a generation consists of $N_{t}$ identical individuals. Members of generation $t$ live with probability $p_{t}$ for two periods and die with probability $\left(1-p_{t}\right)$ at the end of the first period. They work in the first period and are retired during the second one if they survive. Members of generation $t$ choose at date $t$ consumption while young $\left(c_{t}\right)$ and old $\left(d_{t+1}\right)$, as well as the number of their children per adult $\left(m_{t}\right)$, and their consumption of land $\left(v_{t}\right)$. Only a fraction $\eta_{t}$ of the children $m_{t}$ survives.

\subsubsection{The optimization program}

The preferences of members of generation $t$ are represented by the utility function

$$
U\left(c_{t}, d_{t+1}, m_{t}, v_{t}\right)=\Gamma_{1} \ln c_{t}+p_{t} \Gamma_{2} \ln d_{t+1}+\Gamma_{3} \ln \eta_{t} m_{t}+\Gamma_{4} \ln \left(v_{t}-\xi \eta_{t} m_{t}\right)
$$

where $\xi$ is a positive parameter and $\Gamma_{1}+\Gamma_{2}+\Gamma_{3}+\Gamma_{4}=1 .^{3}$

Households maximize their expected utility taking into account the probability of reaching the second period. One can define $\zeta_{t} \equiv v_{t}-\xi \eta_{t} m_{t}$ that measures the services of land per adult. It is increasing with the total amount of land per adult and decreasing with the number of surviving children per adult. Note that only the services coming from land are valued by households. For the same quantity of land services, the utility level is the same whether the agent is owner or leaseholder.

Each newborn child entails a rearing cost of $\phi^{1} w_{t}$. Moreover, for each surviving child, an additional cost of $\phi^{2} w_{t}$ is borne. The dependence with respect to $w_{t}$ is consistent with the fact that the costs of rearing children are proportional to the standard of living of their parents. This may also be

\footnotetext{
${ }^{3}$ We assume $d_{t+1}>1$, in order that an increase of $p_{t}$ rises the utility of an household. It is always possible to rescale consumption units in such a way that $d_{t+1}>1$ without loss of generality.
} 
viewed as the cost of children in time. Thorought the paper $\phi^{1}$ and $\phi^{2}$ are assumed to be constant parameters. ${ }^{4}$

The total cost of children per adult is thus

$$
\left(\phi^{1}+\phi^{2} \eta_{t}\right) w_{t} m_{t}
$$

The number of surviving children per adult is $m_{t}^{\prime} \equiv \eta_{t} m_{t}$. The corresponding cost is $\phi_{t} w_{t} m_{t}^{\prime}$ with

$$
\phi_{t}=\frac{\phi^{1}}{\eta_{t}}+\phi^{2}
$$

Members of generation $t$ maximize their intertemporal utility function under the following budget constraints:

$$
\begin{aligned}
c_{t}+s_{t}+\phi_{t} w_{t} m_{t}^{\prime}+\pi_{t} v_{t} & =w_{t} \\
d_{t+1} & =\frac{\rho_{t+1}}{p_{t}} s_{t}
\end{aligned}
$$

where $s_{t}$ is the amount of savings per young household and $\rho_{t+1}$ is the expected gross rate of return on savings. The actual return is thus $\rho_{t+1}^{\prime} \equiv \frac{\rho_{t+1}}{p_{t}}$ as the savings of the dead agents are redistributed to the surviving ones. This is equivalent to assume the existence of a perfect annuity market.

Note that using $\zeta_{t}$ (the services of land per adult), one can easily make clear the real cost of one surviving child $\left(\phi_{t} w_{t}+\xi \pi_{t}\right)$ which can be broken down as the sum of the cost in time and the cost in land. The intertemporal budget constraint may be rewritten as:

$$
c_{t}+\frac{d_{t+1}}{\rho_{t+1}^{\prime}}+\left(\phi_{t} w_{t}+\xi \pi_{t}\right) m_{t}^{\prime}+\pi_{t} \zeta_{t}=w_{t}
$$

First order conditions for the optimization problem lead to the following solutions:

\footnotetext{
${ }^{4}$ An extension of the model could be to consider that these parameters also follow a dynamical process. For instance the historical evolutions tend to increase $\phi^{2}$, resulting from the end of child work and the increase in education. Estimations of these costs are given in Lindert (1980).
} 


$$
\begin{aligned}
c_{t} & =\gamma_{1, t} w_{t} \\
s_{t} & =\gamma_{2, t} w_{t} \\
d_{t+1} & =\gamma_{2, t} w_{t} \rho_{t+1}^{\prime} \\
m_{t}^{\prime} & =\frac{\gamma_{3, t} w_{t}}{\left(\phi_{t} w_{t}+\xi \pi_{t}\right)} \\
v_{t} & =\frac{\xi \gamma_{3, t} w_{t}}{\left(\phi_{t} w_{t}+\xi \pi_{t}\right)}+\gamma_{4, t} \frac{w_{t}}{\pi_{t}}
\end{aligned}
$$

with

$$
\begin{aligned}
\gamma_{1, t} & =\frac{\Gamma_{1}}{\Gamma_{1}+p_{t} \Gamma_{2}+\Gamma_{3}+\Gamma_{4}} \\
\gamma_{2, t} & =\frac{p_{t} \Gamma_{2}}{\Gamma_{1}+p_{t} \Gamma_{2}+\Gamma_{3}+\Gamma_{4}} \\
\gamma_{3, t} & =\frac{\Gamma_{3}}{\Gamma_{1}+p_{t} \Gamma_{2}+\Gamma_{3}+\Gamma_{4}} \\
\gamma_{4, t} & =\frac{\Gamma_{4}}{\Gamma_{1}+p_{t} \Gamma_{2}+\Gamma_{3}+\Gamma_{4}}
\end{aligned}
$$

As shown in equations (18), (19), (20), and (21), a rise in life expectancy $\left(p_{t}\right)$ increases savings and the propensity to consume in the second period. It decreases first period consumption, fertility, and demand for land.

\subsubsection{Population density}

The number of young households at date $t+1$ is by definition equal to:

$$
N_{t+1} \equiv m_{t}^{\prime} N_{t}
$$

From now on, the lower case designates the upper case variable divided by the number of young households. For instance, $\bar{x}_{t}$ is defined as $\frac{\bar{X}}{N_{t}}$ the quantity of land available per young living agent. The evolution of land per young alive can thus be described by the following equation:

$$
\bar{x}_{t+1}=\frac{\bar{x}_{t}}{m_{t}^{\prime}}
$$




\subsection{Market equilibrium}

\subsubsection{Land markets}

Land has two prices: the rent rate $\pi_{t}$ and the price for sale $q_{t}$. There are thus two markets: one for land services and one for ownership. It is the rent rate $\pi_{t}$ that determines the allocation of rented land between firms and consumers. The equilibrium on the rent market expressed per head of young household is:

$$
v_{t}+x_{t}=\bar{x}_{t}
$$

The price of land for sale $q_{t}$ depends on the global equilibrium on saving market (see below).

\subsubsection{Capital and financial markets}

Total savings have to be shared between physical capital and land.

$$
\gamma_{2, t} w_{t}=m_{t}^{\prime} k_{t+1}+q_{t} \bar{x}_{t}
$$

where $k_{t+1}$ stands for the capital per young household at date $t+1$. The amount of physical capital per young household available in the economy in $t+1$ is thus depending on the value of land $\left(b_{t} \equiv q_{t} \bar{x}_{t}\right){ }^{5}$

At the equilibrium, savings are at least composed of land ${ }^{6}$ and the return on savings is equal to the return on land:

$$
\rho_{t+1}=\frac{q_{t+1}+\pi_{t+1}}{q_{t}}
$$

If capital is used in $t+1$, household savings have to be split into physical capital and land. Thus, the gross return on physical capital has to be equal to the return on land. The arbitrage condition is written as follows:

\footnotetext{
${ }^{5}$ In our model, the use of land services does not directly depend on land ownership. Households and firms may use land services without owning it. This framework is different from Deaton and Laroque (2001), who use more restrictive assumptions. In their model, consumers are required to purchase land to enjoy land services, and there is no market for land renting. Therefore, their portfolio choice between capital and land holdings depends on consumer preferences for land. In our model, utility does not depend on the portfolio choice between land and capital.

${ }^{6}$ This is true even if firms do not use any land, as consumers rent it for housing.
} 


$$
R_{t+1}=\frac{q_{t+1}+\pi_{t+1}}{q_{t}}
$$

If there is no capital in $t+1$, the arbitrage condition does not hold and $R_{t+1}<\frac{q_{t+1}+\pi_{t+1}}{q_{t}}$.

\section{Intertemporal equilibrium}

In this section we analyze the dynamics without capital before turning to dynamics with capital.

\subsection{The dynamics without capital}

We assume that at the beginning of the economy, there is no capital $\left(k_{0}=0\right)$. As we have mentioned before, this phase occurs as long as the marginal productivity of capital is smaller than the return on land $\alpha \lambda A_{t}\left[(1-\lambda) x_{t}\right]^{\alpha-1}<$ $\rho_{t}$. For $K_{t}=0$, equation (8) becomes:

$$
A_{t}=\mu^{\frac{\nu}{\nu-1}}\left(\frac{A_{N}}{\bar{x}_{t}^{\beta}}\right)
$$

Thus, as long as $K_{t}=0, A_{t}$ increases only by the Boserup effect which depends only on the density of population. The competitive wage is given by

$$
w_{t}=(1-\alpha)\left[(1-\lambda) x_{t}\right]^{\alpha}
$$

and marginal productivity of land is

$$
\chi_{t} \equiv \alpha(1-\lambda)\left[(1-\lambda) x_{t}\right]^{\alpha-1}
$$

The firm takes the price of land as given. Thus as long as the firm uses land,

$$
\chi_{t}=\pi_{t}
$$

Equations (29), (30), and (31) are used to obtain new expressions for $m_{t}^{\prime}$ and $v_{t}$ from equations (16) and (17).

$$
\begin{aligned}
m_{t}^{\prime} & =\frac{\gamma_{3, t}(1-\alpha) x_{t}}{\left(\phi_{t}(1-\alpha) x_{t}+\xi \alpha\right)} \\
v_{t} & =\frac{\xi \gamma_{3, t}(1-\alpha) x_{t}}{\left(\phi_{t}(1-\alpha) x_{t}+\xi \alpha\right)}+\gamma_{4, t} \frac{(1-\alpha)}{\alpha} x_{t}
\end{aligned}
$$


Using $v_{t}$ in (24), we obtain:

$$
\left(1+\gamma_{4, t} \frac{(1-\alpha)}{\alpha}\right) x_{t}+\frac{\xi \gamma_{3, t}(1-\alpha) x_{t}}{\phi_{t}(1-\alpha) x_{t}+\xi \alpha}=\bar{x}_{t}
$$

Using $m_{t}$ in (23), we obtain:

$$
\bar{x}_{t+1}=\frac{\phi_{t}(1-\alpha) x_{t}+\xi \alpha}{\gamma_{3, t}(1-\alpha) x_{t}} \bar{x}_{t}
$$

Rearranging (34) and (35), the dynamics of $x_{t}$ is:

$$
\begin{aligned}
& \left(1+\gamma_{4, t} \frac{(1-\alpha)}{\alpha}\right) \frac{\phi_{t}}{\gamma_{3, t}} x_{t} \\
= & \left(1+\gamma_{4, t+1} \frac{(1-\alpha)}{\alpha}\right) x_{t+1}+\frac{\xi \gamma_{3, t+1}(1-\alpha) x_{t+1}}{\phi_{t+1}(1-\alpha) x_{t+1}+\xi \alpha} \\
& -\frac{\xi}{\gamma_{3, t}}\left(\gamma_{3, t}+\gamma_{4, t}+\frac{\alpha}{(1-\alpha)}\right)
\end{aligned}
$$

To characterize the dynamics of the economy, we first assume that the survival probabilities are constant $\left(\eta_{t}=\eta\right.$ and $\left.p_{t}=p\right)$. Thus, $\phi_{t}, \gamma_{1, t}, \gamma_{2, t}$, $\gamma_{3, t}$, and $\gamma_{4, t}$ are also constant and respectively equal to $\phi, \gamma_{1}, \gamma_{2}, \gamma_{3}$, and $\gamma_{4}$. Equation (36) defines the dynamics of $x_{t}$ of the form $x_{t}=f\left(x_{t+1}\right) . \quad f$ is a monotonic increasing function, with $f(0)<0$. Under the assumption of $\gamma_{3}>\phi, f^{\prime}(x)>1$, and there exists a unique positive steady state computed from $(35)$.

$$
x^{*}=\frac{\xi \alpha}{1-\alpha} \frac{1}{\gamma_{3}-\phi}
$$

Following theses properties, the dynamics of $x_{t}$ is determinate and monotonically converge towards $x^{*}$.

If one assumes a low size of population at the beginning of the economy, $\bar{x}_{0}$ is high. From equation (34), it implies that $x_{0}$ is high and greater than $x^{*}$, therefore $x_{t}$, the amount of land per young household used as an input, monotonically decreases from $x_{0}$ to $x^{*}$.

The stationary state is characterized by the following set of equations. Using (37) in (32), (33), (24), (29), (30), and (31), one gets $m^{*}, \bar{x}^{*}, w^{*}$, and $\pi^{*}$. 


$$
\begin{aligned}
m^{*} & =1 \\
\bar{x}^{*} & =\xi+\frac{\xi \alpha}{1-\alpha} \frac{1}{\gamma_{3}-\phi}\left(1+\gamma_{4} \frac{(1-\alpha)}{\alpha}\right) \\
w^{*} & =(1-\alpha)\left[(1-\lambda) \frac{\xi \alpha}{1-\alpha} \frac{1}{\gamma_{3}-\phi}\right]^{\alpha} \\
\pi^{*} & =\alpha(1-\lambda)\left[(1-\lambda) \frac{\xi \alpha}{1-\alpha} \frac{1}{\gamma_{3}-\phi}\right]^{\alpha-1}
\end{aligned}
$$

As $\bar{x}_{t} \equiv \frac{\bar{X}}{N_{t}}$, we also have

$$
N^{*}=\frac{\bar{X}}{\bar{x}^{*}}
$$

Note that $m^{\prime *}=1$ means that the growth rate of population is null as each adult has only one surviving child. As $m^{* *}$ is the net fertility rate, this is consistent with a high gross fertility rate and a high child mortality rate (underdevelopment state). In this regime, there is no technical progress. Fertility levels can increase only if wages increase (cf. equation (16)). As global income is bounded by the decreasing returns on land, and utility increases with the services of land per adult, in the long run output and population are stationary. Note that at the stationary state, population size is proportional to the global endowment in land.

This stationary state exists only if the marginal productivity of capital is smaller than the return on land (i.e. for each $t, \alpha \lambda A_{t}\left[(1-\lambda) x_{t}\right]^{\alpha-1}<\rho_{t}$ ), otherwise the firm starts to accumulate physical capital and we switch to a new regime with capital.

We characterize this condition at the stationary state in order to determine the range of parameters for which the economy stays at the stationary state without capital. From (26) and (23), $\rho_{t+1}$ can be expressed as

$$
\rho_{t+1}=\frac{q_{t+1} \bar{x}_{t+1}+\pi_{t+1} \bar{x}_{t+1}}{q_{t} \bar{x}_{t}} m_{t}^{\prime}
$$

From (25), $q_{t} \bar{x}_{t}=\gamma_{2} w_{t}$. At the stationary state, $m_{t}^{\prime}=1$ and from (29), $(30)$, and (31),

$$
\rho=1+\frac{\alpha}{\gamma_{2}(1-\alpha)} \frac{\bar{x}^{*}}{x^{*}}
$$

Finally, 


$$
\rho^{*}=\frac{1}{\gamma_{2}}\left(\frac{1}{(1-\alpha)}-\gamma_{1}-\phi\right)
$$

The condition $\alpha \lambda A[(1-\lambda) x]^{\alpha-1}<\rho$, can thus be written as:

$$
\begin{aligned}
& \alpha \lambda \mu^{\frac{\nu}{\nu-1}} A_{N} \times\left(\xi+\frac{\xi \alpha}{1-\alpha} \frac{1}{\gamma_{3}-\phi}\left(1+\gamma_{4} \frac{(1-\alpha)}{\alpha}\right)\right)^{-\beta} \\
& \times\left[(1-\lambda)\left(\frac{\xi \alpha}{1-\alpha} \frac{1}{\gamma_{3}-\phi}\right)\right]^{\alpha-1} \\
& -\frac{1}{\gamma_{2}}\left(\frac{1}{(1-\alpha)}-\gamma_{1}-\phi\right)<0
\end{aligned}
$$

The condition under which the economy stays at the stationary state without capital depends on the relative value of the parameters determining: the utility $\left(\gamma_{1}, \gamma_{2}, \gamma_{3}, \gamma_{4}, \xi\right)$, the cost of children $(\phi)$, and the production technology $\left(\alpha, \lambda, \mu, \nu, A_{N}, \beta\right)$ with the cost of children $\phi$ depending on the survival probability of young agents $\eta$ and on the specific costs of children $\phi^{1}$ and $\phi^{2}$ and the $\gamma_{i}$ 's depending on the adult survival probability $p$.

If we consider that all parameters are fixed except $A_{N}, \eta$, and $p$, this condition (44) can be rewritten as

$$
H\left(A_{N}, \eta, p\right)<0
$$

This condition defines a threshold level for $A_{N}$ that is denoted by $\bar{A}_{N}$ such that $H\left(A_{N}, 1,1\right)=0$. Our analysis has produced the following result:

Proposition 1. - If $A_{N}<\bar{A}_{N}$, the economy converges toward a Malthusian underdeveloped equilibrium without capital.

- If $A_{N}>\bar{A}_{N}$, it is still the case if $\eta$ or $p$ are low enough. If $\eta$ and $p$ are high enough, the economy switches to a regime with capital in a finite time. As technical progress increases, capital productivity reaches a level such that investing in capital becomes profitable.

Proof. First we prove that if $\eta$ is low enough, condition (44) is true. $\phi=$ $\frac{\phi^{1}}{\eta}+\phi^{2}$ depends on the infant survival rate parameter $\eta$. As $\phi<\gamma_{3}$, there exists a lower bound on $\eta$ : $\eta_{\text {inf }}=\frac{\phi^{1}}{\gamma_{3}-\phi^{2}}$ and as $\eta$ goes to $\eta_{\text {inf }}, H\left(A_{N}, \eta, p\right) \rightarrow$ 
$-\frac{1}{\gamma_{2}}\left(\frac{1}{(1-\alpha)}-\gamma_{1}-\gamma_{3}\right)<0$. For small values of $\eta\left(\eta\right.$ close to $\left.\eta_{\text {inf }}\right)$, the economy converges toward a Malthusian underdeveloped equilibrium without capital.

Secondly, we prove that if $p$ is low enough, condition(44) is true. $\gamma_{1}, \gamma_{3}$, and $\gamma_{4}$ are decreasing with $p$ and $\gamma_{2}$ increases from 0 to $\Gamma_{2}$ when $p$ increases from 0 to 1 . If $p$ goes to $0, H\left(A_{N}, \eta, p\right) \rightarrow-\infty$. For small values of $p$, the economy converges toward a Malthusian underdeveloped equilibrium without capital.

Third, if $p$ and $\eta$ are high enough, the economy switches to a regime with capital. Indeed, as $H\left(A_{N}, 1,1\right)>0$, the Malthusian stationary state (without capital) no longer exists when $p$ and $\eta$ are sufficiently close to one.

Three parameters may explain a switch from a Malthusian regime without capital to a regime with capital: a technology shock on $A_{N}$, or an increase in the survival parameters $\eta$ and $p$.

An increase of $A_{N}$ has a direct effect on the marginal productivity of capital.

An increase of $\eta$ induces an increase in population size that increases capital productivity by the Boserup effect. As population size increases, the marginal productivity of land also increases as the quantity of land available for production is lower. The first effect always dominates, for $\eta$ high enough. Thus, a reduction of infant mortality may push the economy toward development.

An increase of $p$ (thus a decrease in the adult mortality rate) also induces a switch to a regime with capital. The main effect of an increase in $p$ is an increase in savings. When $p$ is small, the amount of savings is very low. As land is the only asset in which savings can be invested its price is very low. Hence, the return on land is quite high. When $p$ increases the return on land decreases. The return on land cannot be higher than the return on capital any longer when $p$ is high enough. The economy starts to accumulate capital. Thus, a reduction of adult mortality may push the economy towards development.

\subsection{The dynamics with capital}

We first study the existence of a long run path of endogenous growth, and secondly how this growth rate depends on various parameters. 


\subsubsection{Existence of the long run growth rate}

What are the dynamics of the economy if (44) is not true any longer? As the capital stock increases, the economy benefits from technical progress driven by two effects: the previous Boserup effect and the learning by doing effect. The analysis of the dynamics will show the following properties: depending on the value of $A_{K}$ that governs the learning by doing effect, the economy converges either towards a steady state with a constant value for capital, or towards a long run state with a constant endogenous growth rate of capital. In both cases, land is only used by households, and not by the productive sector any more. In the extended model with the CES production function given by (3) simulated in Section 5, the use of land decreases along the growth process.

We start by proving a first result:

Lemma 1. If (44), there does not exist a steady state with both capital and land used in production.

Proof. See Appendix 2

The consequence of this lemma is that two types of long run equilibria can exist in this model. In both cases, no land is used in the production sector. Either the economy converges toward a steady state value of $k_{t}$, or $k_{t}$ undergoes endogenous growth at a rate that tends to some constant value.

Lemma 2. In the long run the dynamics of capital are characterized by

$k_{t+1}=\left(\gamma_{2}-B\right)(1-\alpha) \lambda^{\alpha}\left[\mu\left(\frac{A_{N}}{\bar{x}_{\infty}^{\beta}}\right)^{1-\frac{1}{\nu}}+(1-\mu)\left(A_{K}^{\frac{1}{\alpha}} N_{\infty}^{\left(\frac{1}{\alpha}-1\right)} k_{t}^{\left(\frac{1}{\alpha}-1\right)}\right)^{1-\frac{1}{\nu}}\right]^{\frac{\alpha \nu}{\nu-1}} k_{t}^{\alpha}$

with $B, \bar{x}_{\infty}$ and $N_{\infty}$ depending on $\alpha, \gamma_{2}, \gamma_{3}, \gamma_{4}, \bar{X}, \xi$ and $\phi$ (equations (90), (82), and (83)).

Proof. See Appendix 3.

Proposition 2. Let us define $\bar{A}_{K}$ as

$$
\bar{A}_{K}=\frac{1}{\left(\gamma_{2}-B\right)(1-\alpha) \lambda^{\alpha}(1-\mu)^{\frac{\alpha \nu}{\nu-1}} N_{\infty}^{1-\alpha}}
$$


If $A_{K}<\bar{A}_{K}, k_{t}$ converges in the long run toward a constant value; if $A_{K}>$ $\bar{A}_{K}, k_{t}$ increases at a positive rate in the long run, and the growth factor converges toward a constant value $G^{*}$ with

$$
G^{*}=\left(\gamma_{2}-B\right)(1-\alpha) \lambda^{\alpha}(1-\mu)^{\frac{\alpha \nu}{\nu-1}} A_{K} N_{\infty}^{1-\alpha}
$$

Proof. The proof is straightforward from Lemma 2. In the case $A_{K}>\bar{A}_{K}$, $k_{t}$ increases endogenously with a positive growth rate. In the long run, as the Boserup effect becomes negligible with respect to the learning by doing term, in technical progress $\left(A_{t}\right)$

$$
A_{t}=(1-\mu)^{\frac{\nu}{\nu-1}} A_{K}^{\frac{1}{\alpha}} K_{t}^{\left(\frac{1}{\alpha}-1\right)}
$$

the growth factor of $k_{t}$ tends to $G^{*}=\left(\gamma_{2}-B\right)(1-\alpha) \lambda^{\alpha}(1-\mu)^{\frac{\alpha \nu}{\nu-1}} A_{K} N_{\infty}^{1-\alpha}$.

\subsubsection{Capital accumulation threshold characteristics}

Note that $\bar{A}_{K}$ depends on

$$
N_{\infty}=\frac{\bar{X}}{\xi} \frac{\gamma_{3}-\phi}{\gamma_{3}+\gamma_{4}-\phi}
$$

Thus, condition $A_{K}<\bar{A}_{K}$ depends on the size of land available in the economy $(\bar{X})$. If this size is too low, no endogenous growth can arise in the long run, as land determines an upper bound to the size of the population. Note that a high size for land is not sufficient to get endogenous growth, as other parameters (technology, preferences) matter.

\subsubsection{The growth rate characteristics}

As usual in endogenous growth models with learning by doing driving technical progress, the size of population has a positive effect on the growth rate. This effect is bounded here as population tends to be constant in the long run. This is due to the fixed factor, as in the long run the size of the population is limited by the quantity of land available.

As $N_{\infty}=\frac{\bar{X}}{\xi} \frac{\gamma_{3}-\phi}{\gamma_{3}+\underline{\gamma}_{4}-\phi}$, the ultimate growth rate increases with the quantity of land available $\bar{X}$. This is in line with Romer (1986), and more generally true of all endogenous growth models with a scale effect, where growth depends on the size of the population.

Growth $\left(G^{*}\right)$ also depends on mortality rates as $\gamma_{2}, B$, and $N_{\infty}$ depend on either or both $\eta$ and $p$. 
Lemma 3. $\eta$ has two antagonistic effects on $G^{*}$ given by (47): a negative impact by $\gamma_{2}-B$ and a positive by $N_{\infty}$.

Proof. An increase in $\eta$ induces a decrease in $\phi$. This has two consequences. Firstly, $N_{\infty}$ decreases with $\phi$. Secondly, from (89), one gets

$$
\gamma_{2}-B=\frac{B}{B \frac{1-\alpha}{\alpha}+\left(\gamma_{3}+\gamma_{4}-\phi\right) \frac{1-\alpha}{\alpha}}
$$

This expression shows that $B$ decreases with $\phi$. Indeed, if $B$ increases with $\phi$, the left hand side of (49) decreases with $\phi$, when the right hand side increases, which is a contradiction. Thus $\gamma_{2}-B$ increases with $\phi$.

The intuitions are the following. Firstly, $N_{\infty}$ decreases with $\phi$ : population size in the long run is higher when the cost of children is smaller. Secondly, recall that $\gamma_{2}$ is the saving rate and that only $\gamma_{2}-B$ is invested in capital, while $B$ is invested in land. When the cost of children $\phi$ is smaller, the population size $N_{\infty}$ in the long run is higher and the price of land is higher. Thus the share $\gamma_{2}-B$ invested in capital is lower.

In the end, $\eta$ has two antagonistic effects on $G^{*}$ : a negative impact by $\gamma_{2}-B$ and a positive by $N_{\infty}$. But for plausible numerical values of the parameters the increase in $\eta$ always induces an increase in $G^{*}$.

Lemma 4. $p$ has two antagonistic effects on $G^{*}$ : a positive impact by $\gamma_{2}-B$ and a negative by $N_{\infty}$.

Proof. An increase in $p$ induces an increase in $\gamma_{2}$, and a decrease in $\gamma_{1}, \gamma_{3}$, and $\gamma_{4}$. This has two consequences. Firstly, $N_{\infty}$ decreases with $p$. Secondly, $\gamma_{2}-B$ increases with $p$. Indeed, $\gamma_{2}$ increases with $p$. If $B$ decreases with $p$, the result is obtained. If $B$ increases with $p$, from the right hand side of (49), as $\gamma_{3}$ and $\gamma_{4}$ decrease, $\gamma_{2}-B$ increases.

The intuitions are the following. Firstly, the number of young households in the long run is smaller when the adult life expectancy increases. This is a consequence of the change in households' preferences in favor of second period consumption and to the detriment of other "goods" such as first period consumption, children, and land. Secondly, $\gamma_{2}-B$, that represents the share of saving invested in capital, increases with $p$. This is also a consequence of the change in households' preferences: the increase in life expectancy induces a higher propensity to save in capital.

In the end, $p$ has two antagonistic effects on $G^{*}$ : a negative impact by $N_{\infty}$ and a positive by $\gamma_{2}-B$. But for plausible numerical values of the parameters the increase in $p$ always induces an increase in $G^{*}$. 


\section{The three stages of economic development}

Our framework allows us to describe three phases of economic development: the "Malthusian Regime", the "Take-off Regime", and the "Ultimate Growth Regime".

\subsection{The first phase: the "Malthusian Regime"}

In the "Malthusian Regime", land and labor are the only production factors. There is no capital. Technical progress may increase with the density of population. This "Boserup effect" emphasizes that people try to improve technology when land becomes scarcer. Unfortunately, as long as technical progress is not great enough, it is not incorporated in the production process. Thus, if $A_{N}$ is not high enough (equation (44)), the economy converges towards a steady state in the "Malthusian Regime" with low population, and no capital. The size of land does not affect the consumption levels per agent, as the population is proportional to the land available and as the technology exhibits constant return to scale.

This phase could be viewed as the first millenium in Europe. According to Maddison (2005), total population and GDP per capita were almost constant during this period.

If $A_{N}$ is high enough, the economy starts to accumulate capital, there is no stationary state without capital, and the economy evolves through the second phase.

\subsection{The second phase: The take-off}

In the second phase, as $A_{N}$ is high enough, the economy starts to accumulate capital. Capital accumulation leads to a higher fertility and an increase of the population. Capital is not very high at the beginning and the main driving force of technical progress is the "Boserupian effect". The density of population plays a key role in the accumulation of technical progress and in the take-off of capital accumulation. Nevertheless, this phenomenon is bounded in the model as it relies on population density. Indeed, a too high population density would result in a high price of land, a fall of fertility, and a stabilization of population. So a perpetual growth of population density is impossible.

As the Boserupian effect is bounded, it cannot explain long run growth in the model. But if capital is high enough a "learning by doing" effect arises and technical progress keeps growing, at least for a while. 
If $A_{K}$ is not high enough $\left(A_{K}<\bar{A}_{K}\right)$, the economy converges towards a steady state with constant levels of population, capital and technology. The level of capital may be quite low or quite high depending on the empirical value of $A_{K}$. If $A_{K}$ is low, the level of technology achievable is mainly determined by the "Boserupian effect". If $A_{K}$ is higher but still smaller than $\bar{A}_{K}$, the level of capital and technology achieve a higher level, due to a "learning by doing effect". But this last effect is bounded.

If $A_{K}$ is high enough $\left(A_{K}>\bar{A}_{K}\right)$, the economy goes through the "Boserupian phase" and reaches the "learning by doing" phase. Contrarily to the previous case, the technology does not reach a stationary state. Technical progress grows at a positive rate thanks to the "learning by doing" effect. The capital also keeps growing. This leads to the third phase where capital grows at a constant rate and population is stationary. ${ }^{7}$

The "Boserupian phase" can be viewed in Europe as the period 1000-1700. According to Maddison (2005), there is a small increase in both population and GDP per capita during this period, due to improvements in agricultural productivity.

We may think that the "learning by doing" phase happens at the beginning of the 18th century to the end of the second millenium in Western Europe. During this period, according to Maddison (2005), there is a jump in annual population growth (from $0.08 \%$ in $1600-1700$ to $0.41 \%$ in 1700 1820 and $0.60 \%$ in $1820-1998)$. The annual growth rate of GDP per capita increases from $0.15 \%$ in $1600-1700$ and in $1700-1820$ to $1.51 \%$ in $1820-1998$.

\subsection{The third phase: the "Ultimate Growth Regime"}

If $A_{K}$ is high enough $\left(A_{K}>\bar{A}_{K}\right)$, the economy converges to a state with stationary population and a constant growth rate of capital accumulation defined by equation (47). Land plays a twofold role in this last phase. As the density of population in the long run is $\frac{N_{\infty}}{X}=\frac{1}{\xi} \frac{\gamma_{3}-\phi}{\gamma_{3}+\gamma_{4}-\phi}$, the long run size of population is proportional to the land endowment. $\bar{A}_{K}$ decreases with the size of population (equation (46)) and the growth rate of capital increases with it (equation (47)). Thus, a high land endowment reduces the threshold $\bar{A}_{K}$ to reach the growth regime and increases the long run growth rate when this regime is achieved. This result comes from the scale effect existing in many endogenous growth models as in Romer (1986).

In the very long run, population converges to a stationary state in the

\footnotetext{
${ }^{7}$ The above discussion relies on the parameters $A_{N}$ and $A_{K}$. As condition (44) and $\bar{A}_{K}$ (defined as (46)) both depend on $p$ and $\eta$, the take-off may also appear with reductions in mortality rates.
} 
model. This property comes from the utilization of a fixed factor: land. This is consistent with the United Nations (2004) medium population scenario that expects a stabilization of world total population by 2060. In our model the economy experiences in the very long run both an increase in GDP per capita and a stabilization of total population. This is at odd with the predictions of a lot of growth models that predicts a perpetual population growth, which seems totally unrealistic in a world with limited resources.

\section{$5 \quad$ Numerical examples}

The production function studied above can be viewed as a limit case of a more general Constant Elasticity Substitution production function as mentioned in $(3)$

$$
F\left(K_{t}, L_{t}, X_{t}\right)=\left[\lambda\left(A_{t} K_{t}\right)^{1-\frac{1}{\varepsilon}}+(1-\lambda) X_{t}^{1-\frac{1}{\varepsilon}}\right]^{\frac{\varepsilon \alpha}{\varepsilon-1}} L_{t}^{1-\alpha}
$$

We choose $\varepsilon$ high enough (at least $\varepsilon>1$ ) in order to be close to the theoretical case studied in the previous sections: substitutability between capital $\left(K_{t}\right)$ and land $\left(X_{t}\right)$ is supposed to be high.

As Inada conditions are satisfied for this production function, the firm's problem always has an interior solution.

$$
\begin{aligned}
& R_{t}=F_{K}^{\prime}\left(K_{t}, L_{t}, X_{t}\right) \\
& w_{t}=F_{L}^{\prime}\left(K_{t}, L_{t}, X_{t}\right) \\
& \pi_{t}=F_{X}^{\prime}\left(K_{t}, L_{t}, X_{t}\right)
\end{aligned}
$$

Nevertheless, if one considers numerical values, the economy starts from a situation where $K_{t}$ is nearly null and goes to a situation where $X_{t}$ is nearly null.

\subsection{Dynamics}

Assuming the same behaviors for consumers as in the previous sections, the dynamics of the economy are fully characterized by a system given in Appendix 4 with twelve variables $R_{t}, A_{t}, k_{t}, x_{t}, w_{t}, \pi_{t}, K_{t}, m_{t}^{\prime}, v_{t}, \bar{x}_{t}, q_{t}, N_{t}$. Rearranging the equations without $K_{t}$ and $N_{t}$, and deflating $w_{t}, q_{t}, k_{t}, \pi_{t}$ by $G^{* t}$ and $A_{t}$ by $\left(G^{* t}\right)^{\frac{1}{\alpha}-1}$, we get a dynamic system converging towards a stationary state. Substituting $x_{t}$ by $x_{t}=y_{t}\left(\frac{1}{G^{* t}}\right)^{\frac{\varepsilon-1}{\alpha}}$ for numerical reasons, one gets the simulated system of eleven equations: 


$$
\begin{aligned}
m_{t}^{\prime} & =\frac{\gamma_{3, t} \tilde{w}_{t}}{\left(\phi_{t} \tilde{w}_{t}+\xi \tilde{\pi}_{t}\right)} \\
v_{t} & =\frac{\xi \gamma_{3, t} \tilde{w}_{t}}{\left(\phi_{t} \tilde{w}_{t}+\xi \tilde{\pi}_{t}\right)}+\gamma_{4, t} \frac{\tilde{w}_{t}}{\tilde{\pi}_{t}} \\
\bar{x}_{t} & =y_{t}\left(\frac{1}{G^{* t}}\right)^{\frac{\varepsilon-1}{\alpha}}+v_{t} \\
\gamma_{2, t} \tilde{w}_{t}= & \tilde{q}_{t} \bar{x}_{t}+m_{t}^{\prime} G^{*} \tilde{k}_{t+1} \\
\tilde{q}_{t} \bar{x}_{t}= & \frac{G^{*}}{R_{t+1}}\left(m_{t}^{\prime} \tilde{q}_{t+1} \bar{x}_{t+1+} \tilde{\pi}_{t+1} \bar{x}_{t}\right) \\
G_{t+1}= & G \times G_{t} \\
\tilde{\pi}_{t}= & \alpha(1-\lambda) y_{t}^{-\frac{1}{\varepsilon}}\left[\lambda\left(\tilde{A}_{t} \tilde{k}_{t}\right)^{1-\frac{1}{\varepsilon}}+(1-\lambda)\left(y_{t}\right)^{\left(1-\frac{1}{\varepsilon}\right)}\left(\frac{1}{G_{t}}\right)^{\frac{\varepsilon-1}{\alpha}}\right]^{\frac{\varepsilon \alpha}{\varepsilon-1}-1} \\
\tilde{w}_{t}= & (1-\alpha)\left[\lambda\left(\tilde{A}_{t} \tilde{k}_{t}\right)^{1-\frac{1}{\varepsilon}}+(1-\lambda)\left(y_{t}\left(\frac{1}{G_{t}}\right)^{\frac{\varepsilon}{\alpha}}\right)^{1-\frac{1}{\varepsilon}}\right]^{\frac{\varepsilon \alpha}{\varepsilon-1}} \\
\bar{x}_{t+1}= & \frac{\bar{x}_{t}}{m_{t}^{\prime}} \\
\tilde{A}_{t}= & \alpha \lambda \tilde{A}_{t}^{\left(1-\frac{1}{\varepsilon}\right)} \tilde{k}_{t}^{-\frac{1}{\varepsilon}}\left[\lambda\left(\tilde{A}_{t} \tilde{k}_{t}\right)^{1-\frac{1}{\varepsilon}}+(1-\lambda)\left(y_{t}\left(\frac{1}{G_{t}}\right)^{\frac{\varepsilon}{\alpha}}\right)^{1-\frac{1}{\varepsilon}}\right]^{\frac{\varepsilon \alpha}{\varepsilon-1}-1} \\
& {\left.\left[\frac{1}{G_{t}}\right)^{\frac{1-\alpha}{\alpha}}\left(\frac{A_{N}}{\bar{x}_{t}^{\beta}}\right)\right)^{1-\frac{1}{\nu}}+(1-\mu)\left(A_{K}^{\frac{1}{\alpha}}\left(\tilde{k}_{t} \frac{X}{\bar{x}_{t}}\right)^{\left(\frac{1}{\alpha}-1\right)}\right)^{1-\frac{1}{\nu}} }
\end{aligned}
$$

with eleven variables: $R_{t}, \tilde{A}_{t}, \tilde{k}_{t}, y_{t}, \tilde{w}_{t}, \tilde{\pi}_{t}, m_{t}^{\prime}, v_{t}, \bar{x}_{t}, \tilde{q}_{t}$, and $G_{t}$. The last one $G_{t}$ is exogenous and used only to compute deflated variables.

\subsection{Parametrization and computation}

\subsubsection{Parametrization}

The parameters used to simulate the dynamics to the ultimate growth regime are the following: 


\begin{tabular}{c|ccccc}
\hline \hline Production & $\lambda=0.5$ & $\varepsilon=10$ & $\alpha=0.33$ & & \\
\hline Technology & $\mu=0.5$ & $A_{N}=600$ & $\beta=0.5$ & $\nu=2$ & $A_{K}=50$ \\
\hline Utility & $\Gamma_{1}=0.25$ & $\Gamma_{2}=0.25$ & $\Gamma_{3}=0.25$ & $\Gamma_{4}=0.25$ & $\xi=1$ \\
\hline Cost of a child & $\phi^{1}=0.02$ & $\phi^{2}=0.08$ & & & \\
\hline Fixed asset & $\bar{X}=2.66$ & & & & \\
\hline Life Expectancy & $\eta=1$ & $p=1$ & & & \\
\hline \hline
\end{tabular}

The total cost of one child is ten per cent of wages when all children survive, which is in line with the calculations of Apps and Rees (2001). Recall that the cost in time of one child is $\phi^{1}+\phi^{2} \eta$.

Some simulations are computed below with increasing survival probability scenarios. The figures $\eta=1$ and $p=1$ are the long run values for survival probabilities.

The other parameters have been chosen in order to get in the long run $G^{*}=2$ and $N_{\infty}=1$. If one assumes that a period is thirty years, this leads to an annual growth rate of $2.33 \%$. The population of one generation has been arbitrarily normalized to one in the long run by an appropriate choice of the unit of measure of $\bar{X}$. Note that total population $\left(N_{t+1}+N_{t}+p_{t-1} N_{t-1}\right)$ converges toward 3 in the long run, as our model has three generations living at the same time (children, young agents, and retired people).

\subsubsection{Computation}

Simulations are computed with Dynare, details are given in Adjemian et al. (2011).

We start with the parameter values given above that allow sustained growth at a positive rate $\left(A_{K}>\bar{A}_{K}\right)$. Three difficulties arise in the computation of the dynamic path.

First, one has to compute the long run stationary state. As we simulate an endogenous growth model, there is an hysteresis problem on the long run value $\tilde{k}^{*}$ of $\tilde{k}_{t}$ that depends on the whole path. To compute $\tilde{k}^{*}$, it is necessary to make a loop. We choose an arbitrary value for $\tilde{k}^{*}$ as a terminal condition on $\tilde{k}_{T}$ at period $T$ (the last period of simulations). Starting from the initial value $\tilde{k}_{0}=\tilde{k}^{*}$, the simulation until period $T$ gives a new value of $\tilde{k}^{*}$. This routine is iteratively run until the new calculated $\tilde{k}^{*}$ matches the previous $\tilde{k}^{*}$.

Secondly, we compute trajectories that start from initial conditions away from the stationary state path. This is implemented step by step in order to obtain convergence of the algorithm. At each step, we need new initial values for the computed endogenous variables. We take the ones from the 
last computed path. Obviously, at each step $\tilde{k}^{*}$ is modified as it depends on the whole path and is computed again with a loop.

In the end, initial conditions are set to values corresponding to a steady state with no growth for parameters such that $A_{K}<\bar{A}_{K}$. We then come back to the above set of parameters $\left(A_{K}, p\right.$, or $\left.\eta\right)$ such that $A_{K}>\bar{A}_{K}$, and we simulate the growth trajectory from the initial steady state. The simulated trajectory can thus be interpreted as the growth path resulting from positive shocks on technology or survival probabilities $\left(A_{K}, p\right.$, or $\left.\eta\right)$.

\subsection{Demographic transitions}

We simulate here the transition from a Malthusian steady state to the ultimate growth regime. We examine two possible sources to get out of the Malthusian regime: a technological shock and an increase in survival probabilities. In each case, we generate the corresponding demographic transition.

\subsubsection{Technological shock}

We first examine a technological shock on $A_{K}$ from $A_{K}=10$ to $A_{K}=50$. This permanent shock arises in one period. Nevertheless, it induces dynamics that last six periods on demographic and macroeconomic variables. If one assumes that a period is thirty years, this lasts 180 years. This increase in productivity allows a temporary increase in the fertility rate that leads to a higher population level in the long run. Starting from a steady state with no growth, the technology shock allows a positive GDP growth rate. As the fertility rate falls to the replacement rate in the long run, the GDP per head growth rate catches up with the GDP growth rate.

\section{[PLEASE INSERT FIG. 1 AROUND HERE]}

The shock occurs at date 5 . It has a very small effect on fertility and production at date 5 because the capital stock is fixed at its level of steady state before the shock. Thus, it cannot be seen on the figures. The number of children per adult experiences a dramatic increase at date 6 , that leads to an increase of the number of young households $N$ at date 7 . As the total population incorporates children, it increases right from date 6 .

\subsubsection{Increase in survival probabilities}

We examine progressive positive shocks on the adult survival probability $p_{t}$ (from $p_{t}=0.15$ to $p_{t}=1$ ) and on the child survival probability $\eta_{t}$ (from $\eta_{t}=0.70$ to $\left.\eta_{t}=1\right)$. 
First, we consider only an increase in adult longevity $p_{t}$ from $p_{t}=0.15$ to $p_{t}=1$ in seven periods. This corresponds to an increase in longevity of 25.5 years in 210 years, which is roughly in line with the historical shock observed in western Europe. For $p_{t}=0.15$, the economy is initially in a stationary state with no growth.

The increase in life expectancy incites agents to increase savings which induces long run growth. As technological progress increases, land is less used in production and can be used by households. This leads to a temporary rise in the birth rate and to a higher population level. The initial fall in fertility at the date of the first increase in longevity is due to the increase of the propensity to save $\gamma_{2, t}$ and the corresponding fall in the propensity to make children $\gamma_{3, t}$, which both depend on the adult survival probability $p$.

\section{[PLEASE INSERT FIG. 2 AROUND HERE]}

Secondly, we examine a progressive shock on $p_{t}\left(\right.$ from $p_{t}=0.15$ to $\left.p_{t}=1\right)$ and on $\eta_{t}$ (from $\eta_{t}=0.70$ to $\eta_{t}=1$ ). The increase in $\eta_{t}$ from 0.70 to 1 in seven periods corresponds to a decline in mortality at birth from $30 \%$ to nearly $0 \%$ in 210 years, which is roughly in line with what has been observed historically for developed countries (in France this rate was of 296/1000 in 1740, see Maddison, 2005). The combination of the two shocks doubles the impact on gross fertility and has a noticeable impact on net fertility. Indeed, the decline in infant mortality can be viewed as a reduction in the surviving child costs $\phi$. This increases the number of children. This increase is so fast, that it even induces an overshooting of the size of total population above its long term stationary level.

In the three cases, a dramatic increase in population appears during the take-off phase. This phase lasts between 3 and 6 periods in the model, depending on the scenario considered, thus between 90 and 180 years.

\section{[PLEASE INSERT FIG. 3 AROUND HERE]}

\subsection{Sensitivity of long run growth to the parameter values}

In this section, we analyze the robustness of the results in the long run with respect to different parameter values.

Firstly, we consider the impact of longevity parameters. Lemmata 3 and 4 in section 3.2.3 have shown that $\eta$ and $p$ have undetermined effects on growth in the long run. The two following figures show that they both have a positive effect, for reasonable values of parameters. 


\section{[PLEASE INSERT FIG. 4 AROUND HERE]}

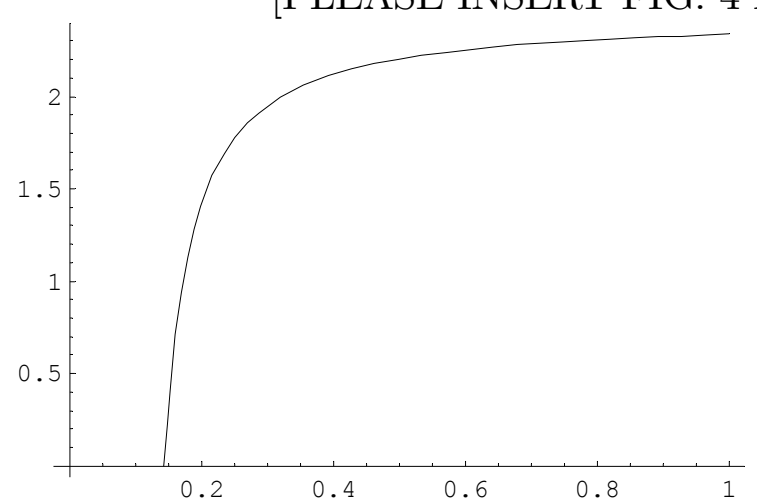

Growth rate with respect to $\eta$

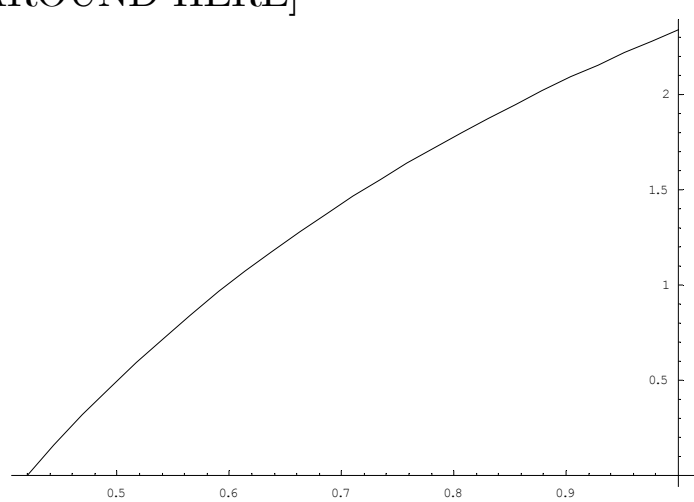

Growth rate with respect to $p$

An increase of $\eta$ tends to rise the size of population in the long run, which has a positive effect on growth. An increase of $p$ tends to rise savings, which plays in favor of capital accumulation.

For both parameters, there exists a threshold level such that the growth rate remains positive in the long run. These threshold values correspond to the value $\bar{A}_{K}=A_{K}$ defined in proposition 2 . Below these thresholds, the economy reaches a stationary state and the long run growth rate is equal to 0.

Secondly, we study the impact of preference parameters. We consider an increase of $\Gamma_{2}$ compensated by a decrease of $\Gamma_{3}$ (in such a way that $\Gamma_{1}+$ $\Gamma_{2}+\Gamma_{3}+\Gamma_{4}=1$, and $\left.\Gamma_{2}+\Gamma_{3}=0.5\right)$. We increase the preference for second period consumption at the expense of the preference for children. As savings and the size of population have both a positive effect on growth, we obtain an inverted U-shaped evolution.

[PLEASE INSERT FIG. 5 AROUND HERE] 


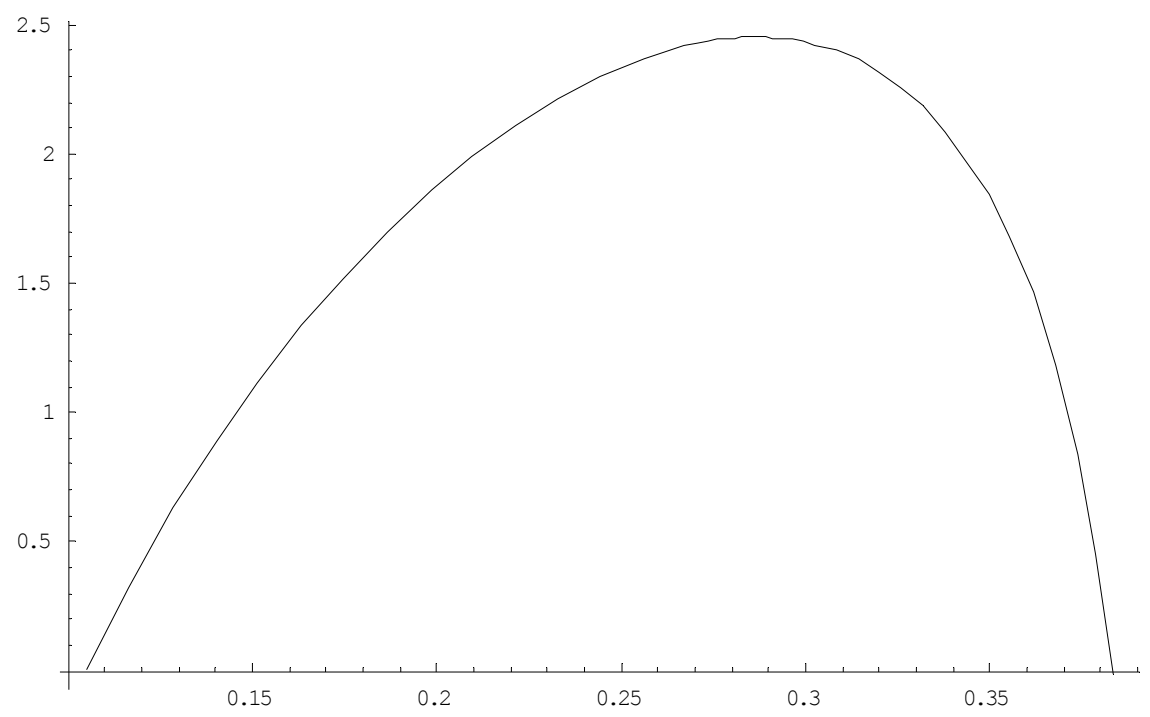

Growth rate with respect to $\Gamma_{2}$, with $\Gamma_{2}+\Gamma_{3}=0.5$

Thirdly, we make a sensitivity analysis on the parameters $\Gamma_{3}$ and $\Gamma_{4}$. We consider an increase of $\Gamma_{3}$ compensated by a decrease of $\Gamma_{4}$ (in such a way that $\Gamma_{3}+\Gamma_{4}=0.5$ ): we increase the preference for children at the expense of the preference for housing. In this case, as $\Gamma_{3}+\Gamma_{4}$ is kept constant, the only effect goes through the increase of population that has a positive impact on growth.

Fourthly, we consider the effect of $\phi_{1}$ and $\phi_{2}$ on long run growth. It is worth noting that the growth rate only depends on $\phi=\phi_{1} / \eta+\phi_{2}$. An increase of $\phi_{1}$ or $\phi_{2}$ reduces the growth rate, as it corresponds to the converse of an increase in $\eta$.

\section{Conclusions}

This paper has developed a new explanation for the evolution of economic and population growth with a long run perspective, emphasizing the role of land in the development process. Starting from a pre-industrialization state called the "Malthusian regime", land and labor are the main production factors. The size of population is limited by the quantity of land available for households and by incomes. Technical progress driven by a "Boserupian effect" may push the economy toward a take-off regime. In this regime, capital accumulation begins and a "learning-by-doing" effect in production takes over from the "Boserupian effect". If this effect is strong enough, the economy can reach an "ultimate growth regime". In the different phases, land plays a crucial role. 
Our analysis could be extended in three directions. First, as mortality rates depend on economic development, they could be endogenized, assuming that they are function of the level of economic development, proxied for example by the aggregate capital stock. Secondly, it could also be relevant to introduce explicit investments in health. This assumption could lead to multiple long run equilibria. The economy could be trapped in underdevelopment resulting from a low survival probability. Thirdly, the model could be extended to replicate historical facts on land price, population density, and growth.

\section{References}

Adjemian S., Bastani H., Juillard M., Mihoubi F., Perendia G., Ratto M. and Villemot S., 2011, Dynare: Reference Manual, Version 4, Dynare Working Papers, 1, CEPREMAP

Aghion P., Howitt P., Murtin F., 2010, "The relationship between health and growth: when Lucas meets Nelson-Phelps", NBER working paper $\mathrm{N}^{\circ} 15813$, March

Apps P., Rees R, 2001, "Household production, full consumption and the costs of children," Labour Economics, Elsevier, vol. 8(6), pp. 621-648, December.

Boserup E., 1965, "The conditions of Agricultural Growth: The Economics of Agrarian Change under Population Pressure", London: Allen \& Unwin.

Boserup E., 1976, "Environment, Population, and Technology in Primitive Societies", Population and Development Review, 1, pp. 21-36.

Brunt L., Garcia-Penalosa C., 2010, "Urbanization and the onset of modern economic growth", mimeo, April.

Deaton A., Laroque G., 2001, "Housing, Land Prices, and Growth," Journal of Economic Growth, vol. 6(2), pp. 87-105, June.

Diamond P., 1965, "Nominal Debt in a Neoclassical Growth Model", American Economic Review 55(5), pp. 1126-50.

Galor O., Moav O., 2004, "From Physical to Human Capital Accumulation: Inequality and the Process of Development", Review of Economic Studies 71, pp. 1001-1026. 
Galor O., Moav O., Vollrath D., 2009, "Inequality in Land Ownership, the Emergence of Human Capital: Promoting Institutions and the Great Divergence", Review of Economic Studies 76 (1), pp. 143-179.

Galor O., Weil D. N., 2000, "Population, Technology and Growth : From the Malthusian Regime to the Demographic Transition", American Economic Review 90 (4), pp. 806-828.

Hansen G., Prescott E., 2002, "Malthus to Solow", American Economic Review 92, No. 4, pp. 1205-1217.

Kongsamut P., Rebelo S., Xie D., 2001, "Beyond Balanced Growth", Review of Economic Studies 68, pp. 869-882.

Kremer M., 1993, "Population Growth and Technological Change: one million B.C. to 1990", The Quarterly Journal of Economics 108, pp. 681716.

Kuznets S., 1960, "Population Change and Aggregate Output," in Demographic and Economic Change in Developped Countries, Princeton University Press, pp. 340-367.

Lindert P., 1980, "Child Costs and Economic Development" in Population and Economic Change in Developing Countries, Editor: Richard A. Easterlin, ed. Chicago University Press, pp. 5-80.

Maddison A., 2005, The World Economy: A Millennial Perspective, OECD.

Malthus T., 1798, An essay on the principle of population, Oxford University Press (1993 printing).

Romer, P., 1986, "Increasing Returns and Long Run Growth", Journal of Political Economy 98, pp. 1002-37.

Rostow W. W., 1959, "The Stages of Economic Growth", Economic History Review 12 (1), pp. 1-16.

United Nations, 2004, World Population to 2300, United Nations, New York. 


\section{Appendix}

\subsection{Appendix 1: Production function}

Along a competitive equilibrium, $L_{t}^{1}$ and $L_{t}^{2}$ are allocated optimally in such a way that total production is maximized. Total production is equal to:

$$
Y_{t}=\left[(1-\lambda) X_{t}\right]^{\alpha}\left(L_{t}^{1}\right)^{1-\alpha}+\left(\lambda A_{t} K_{t}\right)^{\alpha}\left(L_{t}^{2}\right)^{1-\alpha}
$$

Therefore, the optimal allocation results from the program:

$$
\left\{\begin{array}{l}
\max _{\left(L_{t}^{1}, L_{t}^{2}\right)}\left[(1-\lambda) X_{t}\right]^{\alpha}\left(L_{t}^{1}\right)^{1-\alpha}+\left(\lambda A_{t} K_{t}\right)^{\alpha}\left(L_{t}^{2}\right)^{1-\alpha} \\
\text { s. t. } L_{t}^{1}+L_{t}^{2}=L_{t}
\end{array}\right.
$$

The Lagrangian of this program is

$$
\mathcal{L}=\left[(1-\lambda) X_{t}\right]^{\alpha}\left(L_{t}^{1}\right)^{1-\alpha}+\left(\lambda A_{t} K_{t}\right)^{\alpha}\left(L_{t}^{2}\right)^{1-\alpha}+z\left(L_{t}-L_{t}^{1}-L_{t}^{2}\right)
$$

with $z$ the shadow price. The optimality conditions are:

$$
\begin{aligned}
{\left[(1-\lambda) X_{t}\right]^{\alpha}\left(L_{t}^{1}\right)^{-\alpha}(1-\alpha) } & =z \\
\left(\lambda A_{t} K_{t}\right)^{\alpha}\left(L_{t}^{2}\right)^{-\alpha}(1-\alpha) & =z
\end{aligned}
$$

from which we obtain $L_{t}^{1}$ and $L_{t}^{2}$ :

$$
\begin{aligned}
L_{t}^{1} & =(1-\lambda) X_{t}(1-\alpha)^{\frac{1}{\alpha}} z^{\frac{-1}{\alpha}} \\
L_{t}^{2} & =\lambda A_{t} K_{t}(1-\alpha)^{\frac{1}{\alpha}} z^{\frac{-1}{\alpha}}
\end{aligned}
$$

The constraint $L_{t}^{1}+L_{t}^{2}=L_{t}$ allows to calculate the value of $z$ :

$$
z=\left[(1-\lambda) X_{t}+\lambda A_{t} K_{t}\right]^{\alpha} L_{t}^{-\alpha}(1-\alpha)
$$

Finally, the resulting total production can be written, using optimality conditions (64) and (65):

$$
Y_{t}=\frac{z}{1-\alpha}\left(L_{t}^{1}+L_{t}^{2}\right)=\frac{z}{1-\alpha} L_{t}
$$

Replacing $z$ by its value, one gets:

$$
Y_{t}=\left[\lambda A_{t} K_{t}+(1-\lambda) X_{t}\right]^{\alpha} L_{t}^{1-\alpha}
$$




\subsection{Appendix 2: Proof of Lemma 1}

Assume that there exists a steady state with $k>0$ and $x>0$ for (44) not true. At a steady state, $m^{\prime}=1$. From (16), we obtain:

$$
\frac{w}{\pi}=\frac{\xi}{\gamma_{3}-\phi}
$$

and from (17),

$$
v=\xi+\frac{\gamma_{4} \xi}{\gamma_{3}-\phi}
$$

As land is used both by the consumer and the firm, $\chi=\pi$, and equations (4), (5) and (6) become:

$$
\begin{aligned}
w & =(1-\alpha)[\lambda(A k)+(1-\lambda) x]^{\alpha} \\
R & =\alpha \lambda A[\lambda(A k)+(1-\lambda) x]^{\alpha-1} \\
\pi & =\alpha(1-\lambda)[\lambda(A k)+(1-\lambda) x]^{\alpha-1}
\end{aligned}
$$

From (66), the ratio $w / \pi$ is known, which gives:

$$
\frac{w}{\pi}=\frac{1-\alpha}{\alpha(1-\lambda)}[\lambda(A k)+(1-\lambda) x]=\frac{\xi}{\gamma_{3}-\phi}
$$

Defining

$$
\Gamma=\frac{\xi \alpha(1-\lambda)}{\left(\gamma_{3}-\phi\right)(1-\alpha)}
$$

we obtain:

$$
\lambda(A k)+(1-\lambda) x=\Gamma
$$

$w, R$ and $\pi$ can be written:

$$
\begin{aligned}
w & =(1-\alpha) \Gamma^{\alpha} \\
R & =\alpha \lambda A \Gamma^{\alpha-1} \\
\pi & =\alpha(1-\lambda) \Gamma^{\alpha-1}
\end{aligned}
$$

The equilibrium on the rent market gives:

$$
v+x=\bar{x}
$$

The equilibrium on the capital market leads to:

$$
\gamma_{2} w=k+q \bar{x}
$$

The arbitrage condition can be written: 


$$
(R-1) q \bar{x}=\pi \bar{x}
$$

Technical progress

$$
A=\left[\mu\left(\frac{A_{N}}{\bar{x}^{\beta}}\right)^{1-\frac{1}{\nu}}+(1-\mu)\left(A_{K}^{\frac{1}{\alpha}}\left(\frac{k \bar{X}}{\bar{x}}\right)^{\left(\frac{1}{\alpha}-1\right)}\right)^{1-\frac{1}{\nu}}\right]^{\frac{\nu}{\nu-1}}
$$

Finally, the constraints $k \geq 0$ and $x \geq 0$ imply (from (68)):

$$
x \leq \frac{\Gamma}{1-\lambda} \text { and } A k \leq \frac{\Gamma}{\lambda}
$$

and equation (74) is valid only for $R>1$, which implies (from (70):

$$
\alpha \lambda A \Gamma^{\alpha-1}>1
$$

Using (73) and (74), we obtain:

$$
(R-1)\left(\gamma_{2} w-k\right)=\pi \bar{x}
$$

Replacing prices by expressions (69), (70) and (71), and using (72) and (68), we obtain:

$$
\left(\alpha \lambda A \Gamma^{\alpha-1}-1\right)\left(\gamma_{2}(1-\alpha) \Gamma^{\alpha}-k\right)=\alpha(1-\lambda) \Gamma^{\alpha-1}\left[v+\frac{(\Gamma-\lambda A k)}{(1-\lambda)}\right]
$$

Finally,

$$
k=\alpha(1-\lambda) \Gamma^{\alpha-1} v+\alpha \Gamma^{\alpha}+\gamma_{2}(1-\alpha) \Gamma^{\alpha}-\gamma_{2}(1-\alpha) \Gamma^{\alpha} \alpha \lambda \Gamma^{\alpha-1} A
$$

which allows us to express $k$ as a simple function of $A$. All other parameters are known and constant. This expression implies that $A$ must belong to an interval: $\left[0, A_{\max }\right]$ with:

$$
A_{\max }=\frac{\alpha(1-\lambda) \Gamma^{\alpha-1} v+\alpha \Gamma^{\alpha}+\gamma_{2}(1-\alpha) \Gamma^{\alpha}}{\gamma_{2}(1-\alpha) \Gamma^{\alpha} \alpha \lambda \Gamma^{\alpha-1}}
$$

From (75) and as $\nu>1$, it is possible to write:

$$
A \geq \mu^{\frac{\nu}{\nu-1}} A_{N} \bar{x}^{-\beta}
$$

and by $(76) \bar{x}=v+x \leq v+\frac{\Gamma}{1-\lambda}$. Thus:

$$
A \geq \mu^{\frac{\nu}{\nu-1}} A_{N}\left(v+\frac{\Gamma}{1-\lambda}\right)^{-\beta}
$$


To obtain the existence of a steady state with $k>0$ and $x>0$, it is necessary that

$$
A_{\max }>\mu^{\frac{\nu}{\nu-1}} A_{N}\left(v+\frac{\Gamma}{1-\lambda}\right)^{-\beta}
$$

or:

$$
\frac{\alpha(1-\lambda) \Gamma^{\alpha-1} v+\alpha \Gamma^{\alpha}+\gamma_{2}(1-\alpha) \Gamma^{\alpha}}{\gamma_{2}(1-\alpha) \Gamma^{\alpha} \alpha \lambda \Gamma^{\alpha-1}}>\mu^{\frac{\nu}{\nu-1}} A_{N}\left(v+\frac{\Gamma}{1-\lambda}\right)^{-\beta}
$$

Using the expressions of $\Gamma$ and $v$, it is easy to show that this inequality gives (44), which contradicts the assumption. Therefore, there does not exist any steady state with $k>0$ and $x>0$ when (44) is not true. 


\subsection{Appendix 3: Proof of Lemma 2}

Proof. In the long run, land is not used any more in production $\left(x_{t}=0\right)$. Equations (4) and (5) become

$$
\begin{aligned}
w_{t} & =(1-\alpha)\left[\lambda A_{t} k_{t}\right]^{\alpha} \\
R_{t} & =\alpha \lambda A_{t}\left[\lambda A_{t} k_{t}\right]^{\alpha-1}
\end{aligned}
$$

Population is stationary $\left(m_{t}^{\prime}=1\right)$. From $(16)$, one can deduce that

$$
\frac{\pi_{t}}{w_{t}}=\frac{\gamma_{3}-\phi}{\xi}
$$

from (24) that $\bar{x}_{\infty}=v_{\infty}$, and from (17) that

$$
\bar{x}_{\infty}=\xi\left(\frac{\gamma_{3}+\gamma_{4}-\phi}{\gamma_{3}-\phi}\right)
$$

The size of population is:

$$
N_{\infty}=\frac{\bar{X}}{\bar{x}_{\infty}}=\frac{\bar{X}}{\xi} \frac{\gamma_{3}-\phi}{\gamma_{3}+\gamma_{4}-\phi}
$$

Thus, the share of rents in wages is

$$
\frac{\pi_{t} v_{\infty}}{w_{t}}=\gamma_{3}+\gamma_{4}-\phi
$$

The price of land $\left(q_{\infty}\right)$ is computed from $(27)$ :

$$
q_{t} \bar{x}_{t}=\left(q_{t+1} \bar{x}_{t+1}+\pi_{t+1} \bar{x}_{t+1}\right) \frac{m_{t}^{\prime}}{R_{t+1}}
$$

Rewriting (25),

$$
\gamma_{2} w_{t}-q_{t} \bar{x}_{t}=m_{t}^{\prime} k_{t+1}
$$

Dividing, (86) by (85), member by member, one gets:

$$
\frac{\gamma_{2} w_{t}}{q_{t} \bar{x}_{t}}-1=\frac{1}{\frac{q_{t+1} \bar{x}_{t+1}}{R_{t+1} k_{t+1}}+\frac{\pi_{t+1} \bar{x}_{t+1}}{R_{t+1} k_{t+1}}}
$$

In the long run the value of land relative to wages is constant

$$
\frac{q_{t} \bar{x}_{t}}{w_{t}} \equiv B
$$


From (79) and (80),

$$
\frac{q_{t+1} \bar{x}_{t+1}}{R_{t+1} k_{t+1}}=\frac{q_{t+1} \bar{x}_{t+1}}{w_{t+1} \frac{\alpha}{1-\alpha}}=B \frac{1-\alpha}{\alpha}
$$

From (79), (80), and (81)

$$
\frac{\pi_{t+1} \bar{x}_{t+1}}{R_{t+1} k_{t+1}}=\frac{\frac{\gamma_{3}-\phi}{\xi} w_{t+1} \bar{x}_{\infty}}{w_{t+1} \frac{\alpha}{1-\alpha}}=\left(\gamma_{3}+\gamma_{4}-\phi\right) \frac{1-\alpha}{\alpha}
$$

Thus, (87) gives an equation for $B$ :

$$
\frac{\gamma_{2}}{B}-1=\frac{1}{B \frac{1-\alpha}{\alpha}+\left(\gamma_{3}+\gamma_{4}-\phi\right) \frac{1-\alpha}{\alpha}}
$$

Thus, the positive solution of the corresponding second degree equation is:

$$
\begin{aligned}
B= & \frac{1}{2}\left[-\left(\frac{\alpha}{1-\alpha}+\gamma_{3}+\gamma_{4}-\phi-\gamma_{2}\right)\right] \\
& +\frac{1}{2} \sqrt{\left(\frac{\alpha}{1-\alpha}+\gamma_{3}+\gamma_{4}-\phi-\gamma_{2}\right)^{2}+4 \gamma_{2}\left(\gamma_{3}+\gamma_{4}-\phi\right)}
\end{aligned}
$$

Thus, B gives the share of the value of land in wages.Using (88) in (25) allows to calculate the evolution of $k_{t}$ :

$$
k_{t+1}=\left(\gamma_{2}-B\right) w_{t}
$$

From (79)

$$
k_{t+1}=\left(\gamma_{2}-B\right)(1-\alpha) \lambda^{\alpha} A_{t}^{\alpha} k_{t}^{\alpha}
$$

With (8), one can get

$k_{t+1}=\left(\gamma_{2}-B\right)(1-\alpha) \lambda^{\alpha}\left[\mu\left(\frac{A_{N}}{\bar{x}_{\infty}^{\beta}}\right)^{1-\frac{1}{\nu}}+(1-\mu)\left(A_{K}^{\frac{1}{\alpha}} N_{\infty}^{\left(\frac{1}{\alpha}-1\right)} k_{t}^{\left(\frac{1}{\alpha}-1\right)}\right)^{1-\frac{1}{\nu}}\right]^{\frac{\alpha \nu}{\nu-1}} k_{t}^{\alpha}$ 


\subsection{Appendix 4: Simulations}

We provide here the intermediate steps to derive the simulated dynamic system.

Assuming the same behaviors for consumers and the markets as in the theoretical model and the CES production function (3), the dynamics of the economy are fully characterized by the following set of 12 equations:

$$
\begin{aligned}
R_{t} & =\alpha \lambda A_{t}^{\left(1-\frac{1}{\varepsilon}\right)} k_{t}^{-\frac{1}{\varepsilon}}\left[\lambda\left(A_{t} k_{t}\right)^{1-\frac{1}{\varepsilon}}+(1-\lambda) x_{t}^{1-\frac{1}{\varepsilon}}\right]^{\frac{\varepsilon \alpha}{\varepsilon-1}-1} \\
w_{t} & =(1-\alpha)\left[\lambda\left(A_{t} k_{t}\right)^{1-\frac{1}{\varepsilon}}+(1-\lambda) x_{t}^{1-\frac{1}{\varepsilon}}\right]^{\frac{\varepsilon \alpha}{\varepsilon-1}} \\
\pi_{t} & =\alpha(1-\lambda) x_{t}^{-\frac{1}{\varepsilon}}\left[\lambda\left(A_{t} k_{t}\right)^{1-\frac{1}{\varepsilon}}+(1-\lambda) x_{t}^{1-\frac{1}{\varepsilon}}\right]^{\frac{\varepsilon \alpha}{\varepsilon-1}-1} \\
A_{t} & =\left[\mu\left(\frac{A_{N}}{\bar{x}_{t}^{\beta}}\right)^{1-\frac{1}{\nu}}+(1-\mu)\left(A_{K}^{\frac{1}{\alpha}} K_{t}^{\left(\frac{1}{\alpha}-1\right)}\right)^{1-\frac{1}{\nu}}\right]^{\frac{\nu}{\nu-1}} \\
m_{t}^{\prime} & =\frac{\gamma_{3} w_{t}}{\left(\phi_{t} w_{t}+\xi \pi_{t}\right)} \\
v_{t} & =\frac{\xi \gamma_{3} w_{t}}{\left(\phi_{t} w_{t}+\xi \pi_{t}\right)}+\gamma_{4} \frac{w_{t}}{\pi_{t}} \\
N_{t+1} & =\frac{m_{t}^{\prime} N_{t}}{X} \\
\bar{x}_{t} & =\frac{N_{t}}{N_{t}} \\
v_{t}+x_{t} & =\bar{x}_{t} \\
\gamma_{2} w_{t} & =m_{t}^{\prime} k_{t+1}+q_{t} \bar{x}_{t} \\
R_{t+1} & =\frac{q_{t+1}+\pi_{t+1}}{q_{t}} \\
K_{t} & =N_{t} k_{t}
\end{aligned}
$$

with twelve variables $R_{t}, A_{t}, k_{t}, x_{t}, w_{t}, \pi_{t}, K_{t}, m_{t}^{\prime}, v_{t}, \bar{x}_{t}, q_{t}, N_{t}$.

Rearranging the equations without $K_{t}$ and $N_{t}$, one gets the simulated ten equation system: 


$$
\begin{aligned}
& m_{t}^{\prime}=\frac{\gamma_{3, t} w_{t}}{\left(\phi_{t} w_{t}+\xi \pi_{t}\right)} \\
& v_{t}=\frac{\xi \gamma_{3, t} w_{t}}{\left(\phi_{t} w_{t}+\xi \pi_{t}\right)}+\gamma_{4, t} \frac{w_{t}}{\pi_{t}} \\
& \bar{x}_{t}=x_{t}+v_{t} \\
& \gamma_{2, t} w_{t}=m_{t}^{\prime} k_{t+1}+q_{t} \bar{x}_{t} \\
& R_{t+1}=\frac{q_{t+1}+\pi_{t+1}}{q_{t}} \\
& \pi_{t}=\alpha(1-\lambda) x_{t}^{-\frac{1}{\varepsilon}}\left[\lambda\left(A_{t} k_{t}\right)^{1-\frac{1}{\varepsilon}}+(1-\lambda) x_{t}^{1-\frac{1}{\varepsilon}}\right]^{\frac{\varepsilon \alpha}{\varepsilon-1}-1} \\
& w_{t}=(1-\alpha)\left[\lambda\left(A_{t} k_{t}\right)^{1-\frac{1}{\varepsilon}}+(1-\lambda) x_{t}^{1-\frac{1}{\varepsilon}}\right]^{\frac{\varepsilon \alpha}{\varepsilon-1}} \\
& R_{t}=\alpha \lambda A_{t}^{\left(1-\frac{1}{\varepsilon}\right)} k_{t}^{-\frac{1}{\varepsilon}}\left[\lambda\left(A_{t} k_{t}\right)^{1-\frac{1}{\varepsilon}}+(1-\lambda) x_{t}^{1-\frac{1}{\varepsilon}}\right]^{\frac{\varepsilon \alpha}{\varepsilon-1}-1} \\
& A_{t}=\left[\mu\left(\frac{A_{N}}{\bar{x}_{t}^{\beta}}\right)^{1-\frac{1}{\nu}}+(1-\mu)\left(A_{K}^{\frac{1}{\alpha}}\left(k_{t} \frac{\bar{X}}{\bar{x}_{t}}\right)^{\left(\frac{1}{\alpha}-1\right)}\right)^{1-\frac{1}{\nu}}\right]^{\frac{\nu}{\nu-1}} \\
& \bar{x}_{t+1}=\frac{\bar{x}_{t}}{m_{t}^{\prime}}
\end{aligned}
$$

with ten variables $R_{t}, A_{t}, k_{t}, x_{t}, w_{t}, \pi_{t}, m_{t}^{\prime}, v_{t}, \bar{x}_{t}, q_{t}$.

Deflating $w_{t}, q_{t}, k_{t}, \pi_{t}$ by $G^{* t}$ and $A_{t}$ by $\left(G^{* t}\right)^{\frac{1}{\alpha}-1}$, and substituting $x_{t}$ by $x_{t}=y_{t}\left(\frac{1}{G^{* t}}\right)^{\frac{\varepsilon-1}{\alpha}}$. One reaches the simulated system. 


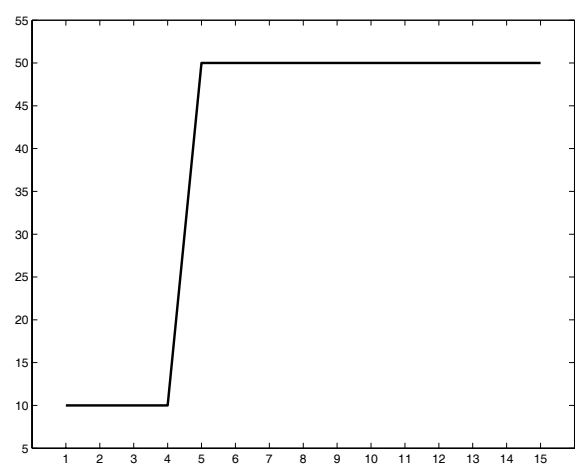

(a) Permanent shock on $A_{k}$

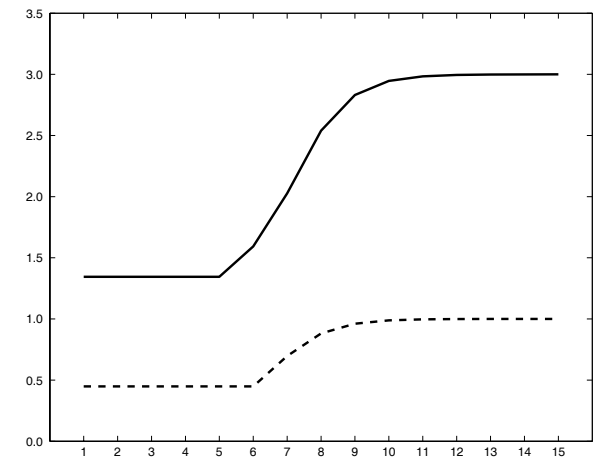

(c) Population

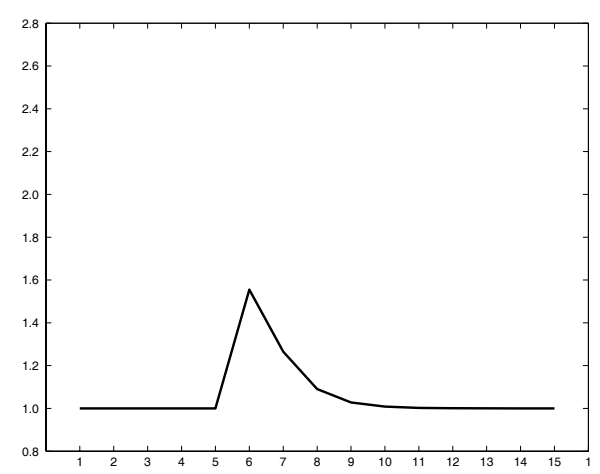

(b) Number of children per adult, $m$

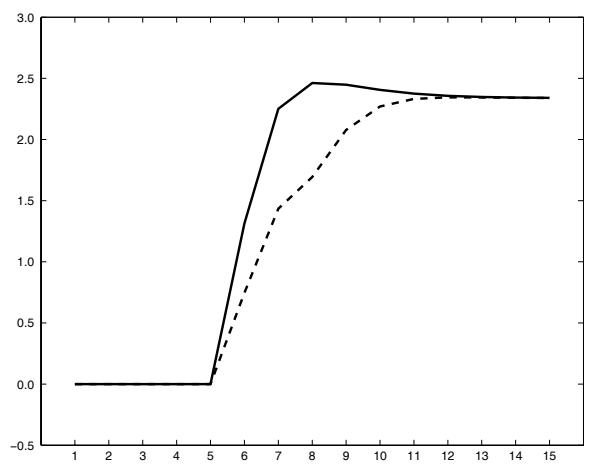

(d) GDP growth rate (\%)

Figure 1: Permanent technological shock. In panel (c), plain and dashed curves are respectively the total population and the number of young agents, $N$. In panel (d), plain and dashed curves are respectively the growth rates of GDP and of GDP per capita. 


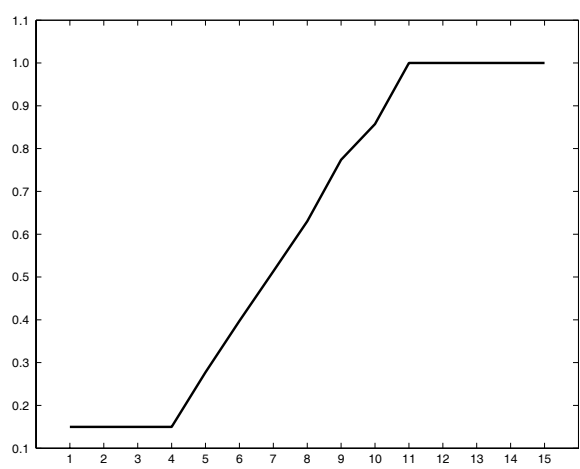

(a) Adult survival probability, $p$

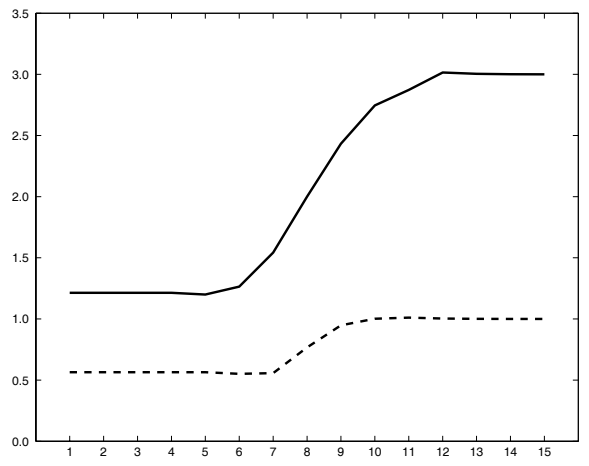

(c) Population

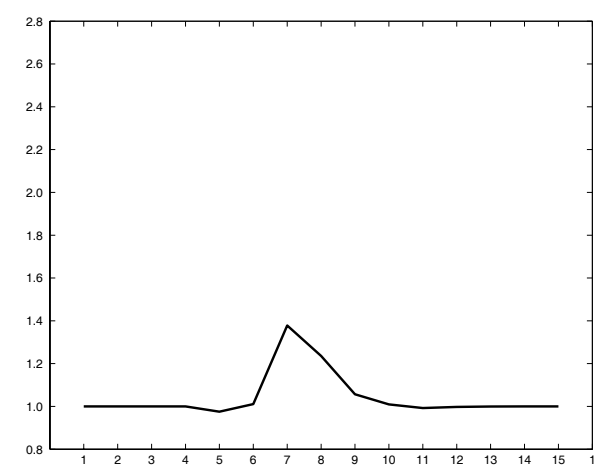

(b) Number of children per adult, $m$

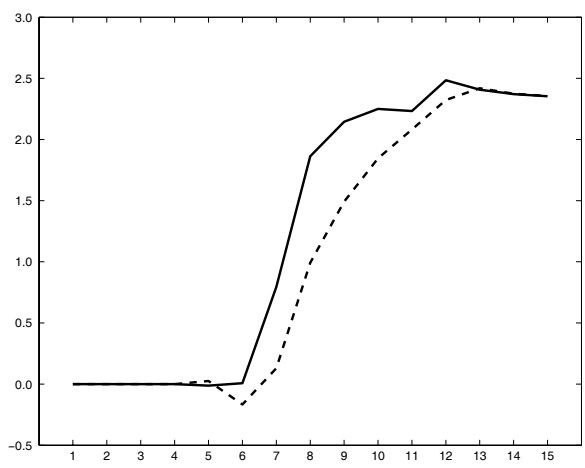

(d) GDP growth rate (\%)

Figure 2: Increase in adult longevity. In panel (c), plain and dashed curves are respectively the total population and the number of young agents, $N$. In panel (d), plain and dashed curves are respectively the growth rates of GDP and of GDP per capita. 


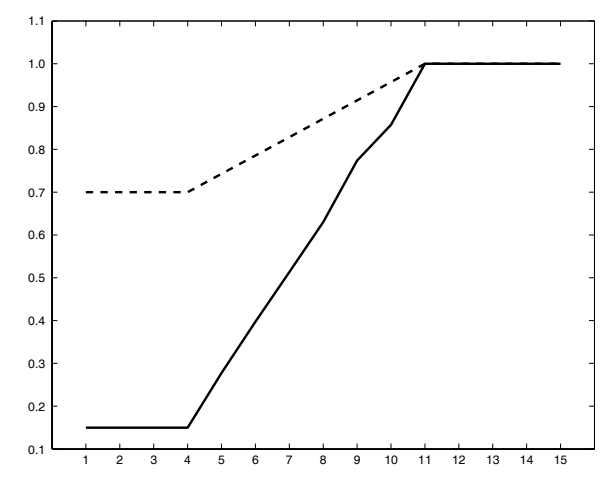

(a) Survival probabilities

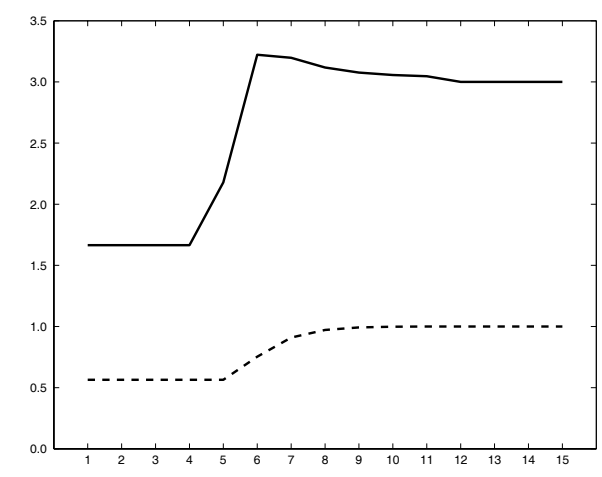

(c) Population

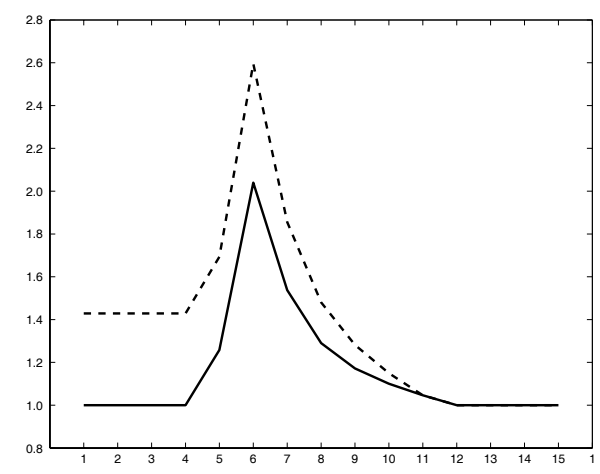

(b) Number of children per adult

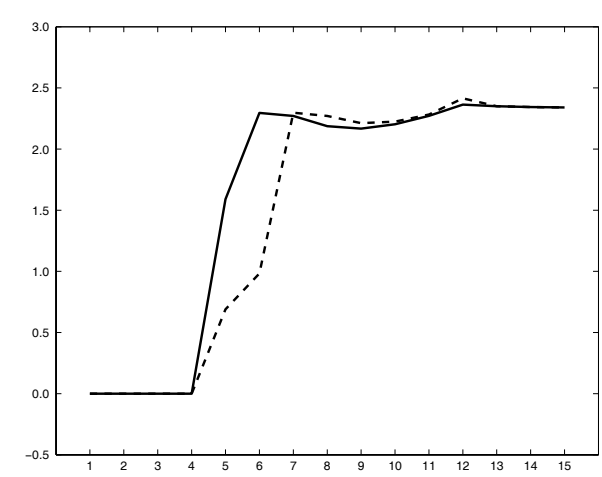

(d) GDP growth rate (\%)

Figure 3: Increase in both survival probabilities. In panel (a), plain and dashed curves are respectively the survival probabilities of adults $(p)$ and of children $(\eta)$. In panel (b), the plain and dashed lines are respectively the number of surviving children per adult $\left(m^{\prime}\right)$ and the total number of children per adult $(m)$. In panel $(\mathrm{c})$, plain and dashed curves are respectively the total population and the number of young agents, $N$. In panel (d), plain and dashed curves are respectively the growth rates of GDP and of GDP per capita. 